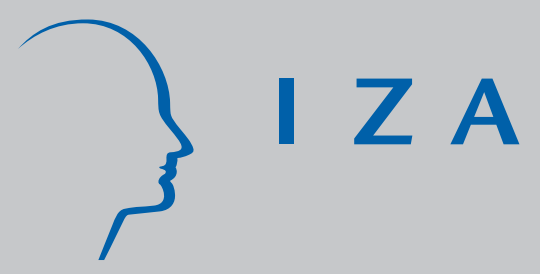

IZA DP No. 3856

The Long-Term Effects of J ob Search Requirements: Evidence from the UKJ SA Reform

Barbara Petrongolo

November 2008 


\title{
The Long-Term Effects of Job Search Requirements: Evidence from the UK JSA Reform
}

\author{
Barbara Petrongolo \\ London School of Economics, \\ CEP, CEPR and IZA
}

\section{Discussion Paper No. 3856 \\ November 2008}

\author{
IZA \\ P.O. Box 7240 \\ 53072 Bonn \\ Germany \\ Phone: +49-228-3894-0 \\ Fax: +49-228-3894-180 \\ E-mail: iza@iza.org
}

\begin{abstract}
Any opinions expressed here are those of the author(s) and not those of IZA. Research published in this series may include views on policy, but the institute itself takes no institutional policy positions.

The Institute for the Study of Labor (IZA) in Bonn is a local and virtual international research center and a place of communication between science, politics and business. IZA is an independent nonprofit organization supported by Deutsche Post World Net. The center is associated with the University of Bonn and offers a stimulating research environment through its international network, workshops and conferences, data service, project support, research visits and doctoral program. IZA engages in (i) original and internationally competitive research in all fields of labor economics, (ii) development of policy concepts, and (iii) dissemination of research results and concepts to the interested public.
\end{abstract}

IZA Discussion Papers often represent preliminary work and are circulated to encourage discussion. Citation of such a paper should account for its provisional character. A revised version may be available directly from the author. 
IZA Discussion Paper No. 3856

November 2008

\section{ABSTRACT}

\section{The Long-Term Effects of Job Search Requirements: Evidence from the UK JSA Reform*}

This paper investigates long-term returns from unemployment compensation, exploiting variation from the UK JSA reform of 1996, which implied a major increase in job search requirements for eligibility and in the related administrative hurdle. Search theory predicts that such changes should raise the proportion of non-claimant nonemployed, with consequences on search effort and labor market attachment, and lower the reservation wage of the unemployed, with negative effects on post-unemployment wages. I test these ideas on longitudinal data from Social Security records (LLMDB). Using a difference in differences approach, I find that individuals who start an unemployment spell soon after JSA introduction, as opposed to six months earlier, are $2.5-3 \%$ more likely to move from unemployment into Incapacity Benefits spells, and $4-5 \%$ less likely to have positive earnings in the following year. This latter employment effect only vanishes four years after the initial unemployment shock. Also, annual earnings for the treated individuals are lower than for the non-treated. These results suggest that while tighter search requirements were successful in moving individuals off unemployment benefits, they were not successful in moving them onto longlasting or better jobs, with fairly long lasting unintended consequences on a number of labor market outcomes.

JEL Classification: J31, J64, J65

Keywords: unemployment compensation, job search, post-unemployment earnings

Corresponding author:

Barbara Petrongolo

Department of Economics

London School of Economics

Houghton Street

London WC2A 2AE

United Kingdom

E-mail: b.petrongolo@lse.ac.uk

\footnotetext{
* I wish to thank Marco Manacorda, Alan Manning, Steve Pischke, John Van Reenen and seminar participants at LSE, NBER Summer Institute, Toulouse, CREST (Paris), Boston University and Columbia University for very helpful comments on earlier drafs. Thanks also to Andrew Needham at the Department for Work and Pension for help with the LLMDB.
} 


\section{Introduction}

Despite a substantial literature on the impact of unemployment insurance (UI) on the duration of unemployment and re-employment rates, ${ }^{1}$ less is known on its long-term effects on work careers. But the channels through which UI affects the process of return to work, mainly job search effort and reservation wages, are clearly also likely to have an impact on the quality of post-unemployment jobs and in general on future work careers. For example it may be argued that more generous UI gives workers the opportunity of not simply accepting the first job offer that comes along, but of waiting for a good job, that provides the best match for their skills.

Since early work by Diamond (1981), a number of papers in the theoretical literature have pointed out that UI may have beneficial effects, mainly by encouraging workers to wait for highproductivity jobs in an environment with search frictions and heterogeneous jobs (Acemoglu, 2001, Acemoglu and Shimer, 1999, 2000, and Marimon and Zilibotti, 1999). However, recent empirical work has generally found little evidence of beneficial effects of UI on post-unemployment earnings or job stability (see Card, Chetty and Weber, 2007a, and references therein).

This paper provides new evidence on the long-term returns from UI, exploiting variation from the UK Jobseekers' Allowance (JSA) reform of 1996. The JSA was introduced in October 1996 to replace the previous Unemployment Benefit/Income Support system, and represented a major reform to the existing UK system of welfare benefits for the unemployed. One of the most important changes with respect to the previous system was a substantial tightening of search requirements for eligibility and in the related administrative hurdle. There is now broad consensus on the strong positive effects of the JSA on the claimant outflow rate. In particular, the months following JSA introduction coincided with a record fall in the number of unemployment benefit claimants.

In this paper I explore the link between tighter search requirements and a number of postunemployment outcomes, including future employment rates, weeks worked, earnings and new benefit spells. The impact of higher search requirements on average search intensity is theoretically ambiguous, as some will search more intensively to meet the requirements, while others may consider the requirements too burdensome and give up search (see Manning, 2005), with an ambiguous impact on the exit rate into new jobs. But the introduction of stricter eligibility criteria unambiguously reduces utility during claimant job search, with negative effects on reservation wages and post-unemployment wages, and raises the share of nonclaimants in the nonemployment stock, thus possibly raising the take-up rate of other kinds of benefits and lowering future employment rates. Experimental evidence for the US indeed tends to show that tighter job search requirements have negative, albeit mild, effects on the time spent of benefits, while the effects on re-employment rates

\footnotetext{
${ }^{1}$ See, among others, Atkinson and Mickewright (1991), Krueger and Meyer (2002) and Meyer (1995) for extensive surveys, and Lalive, van Ours and Zweimüller (2007) for more recent evidence.
} 
are less clear-cut (see Meyer, 1995), thus warning that not all those who are moved off benefits necessarily find new jobs. Related to this point, Card, Chetty and Weber (2007b) find that the spike in the re-employment hazard at benefit exhaustion is much smaller than the spike in the unemployment exit hazard, indicating that many workers leave the unemployment register without returning to work.

I use a difference in differences approach to estimate the effects of unemployment compensation on subsequent careers. I compare long-term outcomes for cohorts of unemployment entrants before and after JSA introduction in October 1996. As these two cohorts may differ in seasonal factors, I construct similar reference cohorts for 1997 and 1998, and then look at difference in differences across cohorts and years.

There is an aspect of the JSA rules that makes this procedure non-standard, namely that when the JSA was introduced, the new eligibility requirements applied not only to the new claimant inflow, but to the existing stock of unemployed claimants as well, so there is no major discontinuity to expect between labor market outcomes of workers who became unemployed just before and just after JSA introduction. But the distance between the start date of an unemployment claimant spell and the date of JSA introduction is indicative of the spell's probability of being treated, and this will be the basis of identification. The key caveat to a causal interpretation of the resulting estimates is that unemployment entry cohorts may differ in unobservable characteristics that affect their post-unemployment outcomes, independently of JSA rules. A related concern is that seasonal factors may vary over time, and thus that differences in differences in labor market outcomes across unemployment entry cohorts and years may not simply pick up the effect of JSA, but also the effect of potential interactions between, say, seasonality and business cycles. I investigate these possibilities with a number of robustness tests. First, for all entry cohorts in 1996-1998, I control for the vacancy to unemployment ratio in the month of unemployment entry, in order to capture the effect of changing aggregate labor market conditions. Second, I run a falsification test on a "placebo" JSA reform in 1997, using 1998 and 1999 entry cohorts to control for seasonal factors. Third, I select entry cohorts in alternative ways and use the quarter of entry as an instrument for the probability of being treated. None of these tests seem to invalidate the results of the main difference in differences estimates.

My empirical analysis leads to three main findings. First, JSA has had a strong, positive and significant impact on the outflow from claimant unemployment for the individuals affected, but a negative impact on weeks worked one year later. While the reform successfully managed to move claimants off benefits, it was not successful in getting them onto new, lasting jobs. Thus it seems that job search requirements mostly worked through raising the non-monetary search effort costs of remaining on UI, rather than enhancing job finding rates. Second, I find that JSA has had a 
negative and significant impact on post-unemployment annual earnings. My estimates indicate an initial impact of about $600 £$ on annual earnings, which persists for as much as 4-5 years after an unemployment shock. Log weekly earnings (conditional on working) are also somewhat reduced by the JSA, although the associated effects are too imprecise to exclude a wide variety of scenarios. Third, while JSA has moved individuals off unemployment-related benefits, it has increased the incidence of other benefits, most notably health-related benefits. Starting a spell soon after JSA introduction, as opposed to six months earlier, implies an increase of $2.5-3 \%$ in the probability of claiming Incapacity Benefits (the equivalent Disability Insurance in the US) six months after unemployment exit.

My work complements existing evidence on the impact of UI on labor market careers by investigating long-run effects of tighter search requirements on post-unemployment outcomes. I use social security data containing complete labor market histories. These allow me to combine information on benefit spells and earnings, and to achieve a more long-term perspective on the impact of UI than previously addressed in the literature. Furthermore, UI systems have several institutional features, and I estimate the effects of major changes in job search requirements, while most of the previous literature focused on the effects of either changes in UI benefit levels or in their maximum duration. As it will be illustrated below, an increase in search requirements is predicted to lower reservation wages and raise exits into nonclaimant nonemployment, even when the actual level of benefits received remains unchanged. Finally, I consider a new potential dimension of the long-term effects of UI, namely the start of other benefit spells, with potential consequences on total benefit expenditure. This relates to a recent literature on higher take-up rates of health-related benefits in a number of countries (see Autor and Duggan, 2003, 2006, for the US; and Faggio and Nickell, 2003 , for the UK).

The paper is organized as follows. The next Section discusses related work. Section 3 describes the JSA features that are going to be relevant in my analysis. Section 4 proposes a simple job search model to represent the likely effects of JSA. Section 5 describes the data set used. Section 6 presents my methodology and some preliminary evidence. Section 7 presents my main findings on the effect of JSA on a number of post-unemployment outcomes and robustness tests. Section 8 finally concludes.

\section{Related work}

This work is related to two main strands of literature on welfare reforms, namely the large existing literature on the impact of tighter job search requirements for UI eligibility on benefit duration, and the less abundant literature on the long-term effects of UI generosity on post-unemployment earnings. 
Evidence on the impact of job search requirements on the time spent of benefits is relevant to the analysis of the paper, as this would naturally represent a kind of first stage for more longterm effects of UI. For instance, if time on benefits did not respond to the tightening of search requirements, it would be hard to expect much effect of this on post-unemployment outcomes. There now exists a large body of experimental work on the effects of increased enforcement of search requirements, based on a number of US social experiments carried out in the late 1970s and 1980s. Meyer (1995) provides an extensive survey and evaluation of these experiments, and finds that the adopted combinations of search requirements and assistance implied some reduction in the number of weeks on benefits. Estimated effects are around half a week for most experiments, and up to 3.3 weeks for the Washington Alternative Work Search Experiment (see also Johnson and Klepinger, 1994). At the same time, the impact on weeks worked tends to be less clear-cut and often imprecisely estimated, suggesting that not all transitions off benefits represents new hires. ${ }^{2}$

For the UK there has been a randomized experiment in 1986, the so-called Restart Programme, which randomly assigned claimants who had spent twelve months of benefits (later reduced to six) to treatment consisting in counseling and tighter enforcement of eligibility requirements, and was essentially a precursor to the JSA, except that the JSA did not include an explicit counselling element. The Restart seems to have significantly increased the exit rate from unemployment (Dolton and O'Neill, 1996) and to have had beneficial long-term employment effects for men treated, though not for women (Dolton and O'Neill, 2002).

A UK-based study of JSA may contribute to the evidence provided by the mostly US-based experimental studies in a number of ways. First, it seems that the JSA had a stronger bite on the claimant unemployment outflow than most US experiments, and thus one may expect that findings from the US social experiments may not necessarily generalize to other scenarios. Second, most existing experiments involve combinations of search requirements and counselling services, and it may be difficult to determine the relative merits of different measures. Finally, the use of social security data in the evaluation of the JSA provides a more long-term perspective on the impact of UI rules and on a wider variety of outcome measures than typically studied in existing work.

The existing literature on the impact of the generosity of UI on post-unemployment outcomes is not as large, and less conclusive. Early studies from the 1970s tend to identify the effect of UI on post-unemployment earnings by exploiting individual variation in the replacement ratio. Among these, Ehrenberg and Oaxaca (1976) look at the effect of the UI replacement ratio on the change in earnings before and after unemployment using data from the US National Longitudinal Survey, and find that a $25 \%$ increase in the replacement ratio yields a $7 \%$ increase in post-unemployment

\footnotetext{
${ }^{2}$ More recent evaluations of US randomized experiments tend to find negative effects of tighter search requirements on UI duration (see for example Klepinger et al., 1997), although in some cases the estimated effect is at most quite small (Ashenfelter et al., 1999). See also the recent survey by Fredriksson and Holmlund (2006).
} 
wages for older men, with lower or non significant effects for other demographic groups. Burgess and Kingston (1976) and Holen (1977) follow a similar approach on Service to Claimants data, and estimate that an extra dollar in weekly benefits raises post-unemployment annual earnings by 25 and 36 dollars, respectively. In contrast, Classen (1977) finds no significant effect of UI on earnings using data on claimants from the Continuous Wage and Benefit History.

It can be argued that exploiting individual variation in replacement ratios is not ideal as this may be correlated with some unobserved individual characteristics, and Cox and Oaxaca (1990) who review this literature tend to dismiss positive findings, and conclude that "one can find no compelling evidence in support of the proposition that UI increases wages because of better matches and increased job stability" (p. 236).

Related studies in the more recent literature are sparse, and tend to conclude that the earnings effects of UI are non-significant or at best very modest. Addison, McKinley and Blackburn (2000) use data from Displaced Worker Surveys and only find (weak) evidence of a favorable impact of UI on post-unemployment earnings when comparing recipients and non-recipients, and even in this case the estimates obtained are substantially smaller than those obtained by earlier studies who found evidence of positive effects. Belzil (2001) and Juraida (2002) look at post-unemployment job duration as a measure of job quality using cohorts of Canadian and US displaced workers respectively. While Belzil finds no causal impact of UI benefit duration on post-unemployment job duration, Juraida finds that UI eligibility actually increases the probability of future layoffs. Card et al. (2007a) exploit discontinuities in severance payments and UI benefit entitlement in Austria, based on previous job seniority, and find no beneficial effects of either transfer on postunemployment earnings or job stability. Similar results are obtained by Van Ours and Vodopivec (2008), who exploit the change introduced by a Slovenian UI reform that substantially reduced the potential benefit duration. Finally, Paserman (2008) estimates a structural job search model, and finds that changes in the level of benefits have negligible impact on re-employment wages, and only affect job finding rates via search intensity.

While the driving variation analyzed by all papers in this literature consists of changes on the level and/or in the potential duration of benefits, I will mostly study the impact of changes in job search requirements, as implied by the JSA reform. As shown in Section 4, these requirements can have an effect on the workers' reservation wages even when the actual level of benefit perceived remains unchanged. Moreover, a tightening of search requirements may raise the number of claimants who leave unemployment without finding a job, and such transitions into "nonclaimant" nonemployment may have more severe consequences on re-employment outcomes, as they typically imply stronger detachment from the labor market than claimant nonemployment. 


\section{The JSA: characteristics and existing evaluations}

The JSA was introduced on 7 October 1996 in order to replace the existing system of Unemployment Benefits (UB) and Income Support (IS). UB represented unemployment insurance, was based on previous social security contributions, and was not means tested. IS was an unemployment assistance scheme that was means tested. The JSA has a contributory component (contJSA), which replaced UB, and a means tested component (incJSA), which replaced IS. ${ }^{3}$

In both the old and the new regime the means-tested component of unemployment compensation was much more important than the contributory component, simply because the majority of unemployment claimants have insufficient social security contributions to be eligible for UB or contJSA, whether at all or in its full duration. For example, only $16 \%$ of unemployed workers receiving benefits in February 1996 were receiving UB, and only 11\% were receiving contJSA one year later in the new regime (see Department for Social Development, 1999, Table 1).

The features of JSA that are relevant for this study are the changes introduced with respect to the previous UB/IS system, and the transitional arrangements for individuals receiving either UB or IS when JSA came into action. ${ }^{4}$ JSA introduction implied some changes in the duration and level of benefits. UB had a maximum entitlement period of 12 months, and this was halved to 6 months under JSA. In 1996 UB was $£ 48.25$ per week for single persons, with a $£ 29.75$ adult dependant supplement, while IS was $£ 47.90$ for single persons aged $25+, £ 37.90$ for single persons aged $18-24$, and $£ 75.20$ for couples in which at least one spouse was aged $18+.^{5}$ Thus UB and IS payments were very similar except for young people, who received about $20 \%$ less under IS than UB. When JSA was introduced it was initially payable at exactly the same rates and conditions as IS. Thus the only category who saw their benefits cut in the new JSA regime consisted of youths who would have been eligible for UB under the old regime. But because the proportion of UB recipients was low, this change had an arguably limited impact. Nevertheless, all the results below are presented separately for the 16-24 and the 25-64 year old groups.

The most significant break with respect to the previous UB/IS regime was represented by the substantial increase in job search requirements for eligibility and in the related administrative hurdle. Claimants have to sign a Jobseeker's Agreement, to be agreed with an Employment Officer, in which they commit to actively seek work and to a number of specific search steps in order to

\footnotetext{
${ }^{3}$ After JSA introduction there is still a benefit called IS, but it is not job-search related, and provides means-tested welfare to selected demographic groups, most notably lone parents and carers of dependants with disabilities.

${ }^{4} \mathrm{~A}$ very detailed description of institutional and administrative aspects of the JSA is contained in the Jobseeker's Handbook by Pointer and Barnes (1997). The pre-existing UB/IS system is covered by Finn et al. (1996).

${ }^{5}$ In 1996, IS is payable at the full rate to individuals with savings below $£ 3,000$, at a reduced rate to individuals with savings between $£ 3,000$ and $£ 8,000$, and is not payable to those with savings in excess of $£ 8,000$. 16 and 17 year olds were eligible for the $£ 37.90$ IS rate if living away from their parents or qualified for a disability premium; otherwise were entitled to a $£ 28.85$ reduced rate.
} 
find work, like how may employers at least they are going to contact every week, or how many times at least they are going to contact a Jobcentre (see Poynter and Barnes, 1997, pp. 355-358). They are required to keep a detailed diary of search steps undertaken, such as each phone call made to a potential employer. The search diary is then checked against the initial agreement at fortnightly interviews with the Employment Service, or more often if a claimant is suspected of fraud. Claimants may be "directed" by the Employment Service staff to take specific steps, and if a claimant is still unemployed after 13 weeks, he is required to broaden his search and may not turn down job offers outside his main occupation. While it can be argued that these measures are hardly enforceable, in so far one has control on job offers received, it is possible that JSA may have made an impact by introducing extra administrative hurdle and requiring more intensive contact with the Employment Service. Evidence from social experiments has shown that in some cases a substantial proportion of UI claimants who are selected for treatment involving both monitoring and assistance in job search do not attend mandatory re-employment services and thus drop out of the claimant count (see Dolton and O'Neill, 2002, for the UK and Johnson and Klepinger, 1994, and Black et al, 2003, for the US). This effect may, if anything, be even stronger for the JSA, which does not offer any active job search assistance service.

Although the new JSA rules fit in a trend of tighter eligibility for unemployment compensation, started in 1986 with the Restart Programme for those unemployed longer than twelve months, JSA introduction represented a marked change in entitlement rules and in required interaction with the Employment Service. In its current format, the UK unemployment compensation scheme has much stronger emphasis on search requirements than the US scheme, but, unlike the US scheme, it has potentially unlimited duration, subject to a means test. ${ }^{6}$

As this work is mostly going to focus on cohorts of unemployment entrants during the year of JSA introduction, transitional arrangements from the UB/IS system to the JSA are going to play an important role in my choice of methodology. During the pre-JSA period, all UB spells started on or before 8 April 1996 and before 7 October 1996 had a maximum 6 (instead of 12) months entitlement at the UB rate. More importantly, all existing UB and IS spells as of 7 October 1996 are transferred to the JSA system, and claimants had to fill a Jobseeker's Agreement soon after 7 October, and "were treated as having made a Jobseekers' Agreement until the date in which an actual Agreement is made" (Finn, Murray and Donnelly, 1996, p.64), using information provided in their initial UB or IS form. The retroactive applicability of JSA was very much in the spirit to sanction "those who were not previously assiduous in their job search or were claiming fraudulently" (Rayner et al, 2000, p1).

\footnotetext{
${ }^{6}$ Despite the difference in search requirements, Krueger and Mueller (2008) find that the average unemployed worker in the US devotes about 41 minutes to job search on weekdays, while his/her UK counterpart devotes 8 minutes on average.
} 
The JSA has been generally perceived as a major reform of the UK welfare system for the unemployed, and some of its effects can be easily grasped by looking at time series of seasonally adjusted flows in and out of registered unemployment, shown in Figure 1. Soon after JSA introduction, there was a marked increase in the claimant outflow, with little or no impact on the inflow into the claimant register. As the solid line is Figure 2 shows, this translated into a more rapid decline in the claimant unemployment stock, which was already falling in the months preceding the reform. However, the dashed line in Figure 2 shows that around the same time the standard ILO measure of unemployment was falling less markedly, and while the two series were quite close during the first half of the 1990s, ILO unemployment has remained much higher than the claimant count since the late 1990s. Part of the reason why ILO unemployment was not falling as sharply around the time of JSA introduction is that some of those who were leaving the register did not move straight into employment.

Another interesting piece of evidence is the comovement between the claimant count and the number of individuals on Incapacity Benefits. Figure 3 plots these two series since $1995 .{ }^{7}$ Although the rise in the IB roll during the sample period was much smaller than the fall in registered unemployment, the two series are strongly negatively correlated $(\rho=-0.874)$, and thus it makes sense to look into possible spillovers on the IB take up rate when there is a sharp fall in registered unemployment.

Official evaluations of the JSA carried by the then Department of Social Security (now Department for Work and Pension) agree in documenting a very strong impact of the JSA on the flow off the unemployment claimant register, see for example Rayner et al. (2000) and Smith et al. (2000). More recently, McVicar (2008) studies a case of excused signing (and thus zero monitoring of search effort) within the JSA, during refurbishment of benefit offices in Northern Ireland, and finds that periods with no monitoring strongly reduce the exit rate from benefits.

However, optimistic conclusions on job search and employment effects of search monitoring do not seem to be granted. Closely related to this work, Manning (2005) finds in fact that the JSA did not result in an overall increase in job search effort, nor in higher job-finding rates. The next section illustrates how these developments may in turn result in lower post-unemployment earnings and/or higher exits from the labor force.

\section{A job search model}

A simple job search model is a useful framework to illustrate the likely impact of higher job search requirements on post-unemployment outcomes. Manning (2005) proposes a search model

\footnotetext{
${ }^{7}$ Aggregate quarterly data on IB recipients become available through the Department for Work and Pensions only for 1995 onwards.
} 
to represent the effects of tighter search requirements on optimal search effort. His model is in the wage posting tradition, with an exogenous wage distribution and endogenous search effort, as in Mortensen (1986). Below I use a very similar framework to illustrate post-unemployment outcomes such as earnings and transitions out of the labor force. In doing this I assume that only the unemployed search for jobs, as this is the key aspect affected by the JSA reform, while employed job search, though empirically important, would not affect the relevant predictions of the model.

Individuals are infinitely lived, and maximize lifetime utility in continuous time. They can be either employed or unemployed. When unemployed, they are paid unemployment compensation $b$, and spend job search effort $s$, assuming for the moment that $b$ is not conditional on $s$. Search effort in turn $\operatorname{costs} c(s)$ and generates job offers at rate $\lambda(s)$. It is typically assumed that search costs are convex in effort, while returns are concave, thus $c^{\prime}(s)>0, c^{\prime \prime}(s)>0, \lambda^{\prime}(s)>0$, and $\lambda^{\prime \prime}(s)<0 .{ }^{8}$ Offers are random draws from an exogenous, known distribution $F(w)$. When employed, individuals are paid a wage $w$ and face an exogenous risk of job loss $\delta$.

Given this environment, the unemployed choose an optimal job search effort level $s$, and a reservation wage $w_{R}$, representing the lowest acceptable wage offer. The flow value of unemployment and employment can be written as follows, respectively:

$$
\begin{aligned}
r U & =\max _{s, w_{R}}\left\{b-c(s)+\lambda(s) \int_{w_{R}}[W(w)-U] d F(w)\right\} \\
r W(w) & =w+\delta[U-W(w)],
\end{aligned}
$$

where $r$ represents the intertemporal discount rate.

The reservation wage is defined by $r W\left(w_{R}\right)=r U$, i.e. it is the level of the wage that makes employment equally valuable as unemployment, and given (1) this also implies $r U=w_{R}$, i.e. the flow value of unemployment is equal to the reservation wage. Using integration by parts to rewrite (1), and noting that $W^{\prime}(w)=1 /(r+\delta)$, the reservation wage is implicitly defined by

$$
w_{R}=r U=\max _{s}\left\{b-c(s)+\frac{\lambda(s)}{r+\delta} \int_{w_{R}}[1-F(w)] d w\right\} .
$$

Search effort is set optimally at the level that equates the marginal costs of search with the marginal benefits, represented by the higher arrival rate of offers, times the associated net gain with respect to unemployment:

$$
c^{\prime}\left(s^{*}\right)=\frac{\lambda^{\prime}\left(s^{*}\right)}{r+\delta} \int_{w_{R}}[1-F(w)] d w .
$$

The key step is to observe how utility while unemployed and thus the reservation wage respond to benefits and search effort. The reservation wage clearly increases with $b$, as unemployment

\footnotetext{
${ }^{8}$ For the existence of an interior solution in $s$ in a model with constant $b$ it is sufficient that either $c^{\prime \prime}(s)>0$ or $\lambda^{\prime \prime}(s)<0$.
} 
income is forgone when one finds a job. Formally:

$$
\frac{d w_{R}}{d b}=1-\frac{\lambda(s)}{r+\delta}\left[1-F\left(w_{R}\right)\right] \frac{d w_{R}}{d b}=\frac{r+\delta}{r+\delta+\lambda(s)\left[1-F\left(w_{R}\right)\right]}>0
$$

The effect of search effort on the reservation wage is positive for $s<s^{*}$ and negative for $s>s^{*}$ :

$$
\frac{d w_{R}}{d s}=\frac{r+\delta}{r+\delta+\lambda(s)\left[1-F\left(w_{R}\right)\right]}\left\{\frac{\lambda^{\prime}(s)}{r+\delta} \int_{w_{R}}[1-F(w)] d w-c^{\prime}(s)\right\} .
$$

Conditions (5) and (6) imply indifference curves in $s$ and $b$ like those drawn in Figure 4, where higher curves are associated with higher levels of utility. Figure 4 also depicts the effect of a fall in $b$, resulting into lower reservation wages, and higher search effort. This latter effect is given by

$$
\frac{d s^{*}}{d b}=\frac{\lambda^{\prime}\left(s^{*}\right) \int_{w_{R}}[1-F(w)] d w}{r+\delta+\lambda\left(s^{*}\right)\left[1-F\left(w_{R}\right)\right]}\left[\frac{\lambda^{\prime \prime}\left(s^{*}\right)}{r+\delta} \int_{w_{R}}[1-F(w)] d w-c^{\prime \prime}\left(s^{*}\right)\right]^{-1}<0 .
$$

The rate at which the unemployed find work is $h=\lambda\left(s^{*}\right)\left[1-F\left(w_{R}\right)\right]$. Thus a reduction in $b$ raises the job finding rate via both an increase in job search effort (and thus in the arrival rate of offers) and a reduction in the reservation wage (and thus a fall in the rejection rate). At the same time, it lowers the expected post-unemployment wage, $E\left(w \mid w>w_{R}\right)$.

The discussion so far assumed constant benefits, unconditional on search effort. Let's assume now that unemployment benefits are only paid above a certain threshold of search effort, $\underline{s}$. Individuals whose search effort exceeds or is equal to $\underline{s}$ are formally classified as UI claimants, while individuals with search effort below $\underline{s}$ are nonclaimants, and typically receive lower income than claimants. This however is not necessarily zero in expected value if nonclaimants face some positive probability to receive benefits that are not search related (like housing or health-related benefits). In this context the introduction of JSA can be represented as an increase in $\underline{s}$.

Consider indifference curves such as those represented in Figure 5. The increase in requirements from $\underline{s}_{1}$ to $\underline{s}_{2}$ would raise search effort from $s_{1}^{*}$ to the corner solution $s_{2}^{*}=\underline{s}_{2}$, and would move individuals on to a lower indifference curve, characterized by a lower reservation wage. As a consequence job finding rates are higher, and these are precisely the "intended" consequences of the JSA. Consider now an individual whose initial search effort is lower, as illustrated in Figure 6, such that he barely meets the more lenient requirements, i.e. $s_{1}^{*}=\underline{s}_{1}$. With the new requirements he would actually reduce his search effort. In other words, not only would he not meet the new requirements $\underline{s}_{2}$, but also it would no longer be worthwhile for him to keep his search effort as high as $\underline{s}_{1}$, thus $s_{2}^{*}<s_{1}^{*}$. With lower reservation wages and lower search effort, the effect of the increase in search requirements on the job finding rate of the unemployed is ambiguous. These could be some "unintended" consequences of the JSA.

This framework delivers two main results that are going to be relevant for the empirical analysis that follows. First, changes in $\underline{s}$ affect the composition of the nonemployed between UI claimants 
and nonclaimants. To see this, note that changes in $\underline{s}$ do not affect optimal search intensity for workers with either very high initial search effort, i.e. $s_{1}^{*} \geq \underline{s}_{2}$, or very low initial search effort, i.e. $s_{1}^{*}<\underline{s}_{1}$. The former will be UI claimants in both regimes, while the latter will always be nonclaimants. But workers who pick initial search effort in the middle range $\underline{s}_{1} \leq s_{1}^{*}<\underline{s}_{2}$ are affected by the change in search requirements. All of them are initially claiming UI; some of them will find it optimal to search harder when $\underline{s}$ is raised (as in Figure 5), and keep claiming UI; while others will reduce search effort (as in Figure 6), and stop claiming UI in the new regime. This implies that an increase in $\underline{s}$ will raise the share of nonclaimants among the nonemployed population. They can be either nonclaimant unemployed ${ }^{9}$ or nonparticipants, and may or may not receive benefits that are not job search related. Clearly, the change in the composition of the nonemployed is more important the stronger the rise in eligibility requirements, $\underline{s}_{2}-\underline{s}_{1}$.

Second, whether optimal search effort increases (Figure 5) or decreases (Figure 6), utility enjoyed when unemployed unambiguously falls as a consequence of an increase in $\underline{s}$, and this holds even when the actual level of benefits received remains unchanged. This happens because some cash payments that were initially made to the unemployed without too much questioning are now made conditional on substantial search effort, with some associated costs. Thus one would expect that an increase in $\underline{s}$ lowers reservation wages and the quality of post-unemployment jobs.

Interestingly, the relative magnitude of these two effects depends on the loss of income upon leaving claimant unemployment, $b_{2}-b_{1}$. When such difference is relatively high, individuals are less likely to leave the claimant count for nonclaimant nonemployment, and even conditional on staying on benefits, they experience a higher utility loss, with stronger consequences on reservation wages and re-employment wages. On the other hand, when the $b_{2}-b_{1}$ difference is low, the impact on reservation wages is moderate, but even a small increase in search requirements would push claimants off the register, with stronger consequences on the composition of nonemployment. In the UK institutional context, the $b_{2}-b_{1}$ difference is probably not very large, considering that unemployment benefits at the time of JSA introduction were only $£ 47.90$ per week, ${ }^{10}$ and that upon loss of these benefits individuals could apply for other kinds of benefits, which are not search related. Thus one may expect the JSA effects on the composition of nonemployment to be more important than its effects on reservation wages and postunemployment wages.

Finally, if on top of higher search requirements, the level of benefits is also falling, as it was the case for workers aged 18-24 who were receiving UB before JSA introduction, this generates a stronger fall in the reservation wage (as shown in Figure 4), and lowers the incentive to raise search

\footnotetext{
${ }^{9}$ To fall in this category, a worker may not meet the JSA search requirements but meet instead the ILO unemployment definition, which classifies as unemployed those who have not worked more than one hour during the reference period but who are "available for and actively seeking work".

${ }^{10}$ Using gross weekly earnings for UK men in 1996Q4 as reference, this implies a replacement ratio of about $14 \%$.
} 
effort and meet the higher requirements, thus raising the proportion of workers who reduce search effort as a consequence of JSA introduction. Thus any fall in the level of benefits would simply reinforce the effects of tighter search requirements on both post-unemployment wages and outflows into nonclaimant unemployment.

\section{Data}

The data used in this paper are drawn from the Lifetime Labour Market Database (LLMDB), administered by the Department for Work and Pensions. The LLMDB represents a $1 \%$ random sample of social security records in Great Britain. Individuals covered are those whose National Insurance numbers end in two given digits. The LLMDB provides a rich set of information on labor histories of selected individuals from 1978 onwards. In particular, it has the advantage of linking information on benefit spells with information on earnings.

Specifically, the LLMDB provides start and end dates of benefit spells, together with their type. Types include job-search related benefits, like UB and IS in the old system and JSA in the new system; health related benefits, like Incapacity Benefits (IB) or the Disability Living Allowance (DLA); in-work benefits, like the Working Family Tax Credit (WFTC); retirement pensions; maternity allowances; and a few others.

All information on benefit spells is in principle available since 1978, but the quality of benefit spells data until 1995 is poorer than for the later period. For example, benefit spells seem to be under-reported for the earlier period, and a relatively large proportion of them has missing, or imputed, end dates.

I use unemployment claimants spells for 1996, 1997 and 1998. The LLMDB reports 66,707 unemployment benefit spells started by British males between 1 January 1996 and 31 December 1997. According to the UK Official Labour Market Statistics (Nomis), the male unemployment inflow in the same period was $6,725,595$. When LLMDB sampling is taken into account, the figures stemming from the two sources are closely comparable.

Having said this, even in the post 1995 period, the accuracy of information on end dates of spells is poorer than that on start dates. In particular, the IS end dates have very strong quarterly spikes. This happens because all relevant information about IS spells is collected quarterly by the Department for Work and Pensions; thus if an individual features in the sample with an ongoing IS spell at the start of a given quarter, but is not on IS at the end of the quarter, he is assigned an imputed completion date corresponding to the middle date of the quarter. As typically IS spells follow UB spells, this bunching problem is going to produce spikes in the end dates of unemployment spells in my sample in the pre-JSA regime. For this reason I choose to minimize the use of the end date of spells in the empirical analysis, and all selection criteria used are based on spells start 
dates.

In the pre-JSA regime I construct unemployment spells by linking together UB and IS spells that (partly) overlap, and UB and IS spells that do not overlap but have a maximum two weeks window between the end date of the former and the start date of the latter. This is because a spell out of benefits of less than two weeks is highly unlikely to represent a short job spell, and thus for my purpose the corresponding benefit spells sequence best represents a single unemployment spell. Also, bureaucratic procedures may require some time to move a claimant from unemployment insurance to unemployment assistance benefits, and this may explain some short gap between benefit spells. However, the results obtained are not sensitive to shortening such window to 7 or zero days.

Information on employment and income is provided by fiscal years. Fiscal years in the UK start on 6 April of a given year and end on 5 April of the following year, and in what follows all annual indicators reported refer to fiscal, rather than calendar years. Employment and income are represented by annual weeks worked and annual pre-tax pay, respectively. Both measures are available from 1978 onwards. However, it should be noted that while from 1999 onwards the number of weeks worked is reported directly within each National Insurance file, this has been estimated by the Department for Work and Pensions for the period 1978-1998 using information on known periods of nonemployment and self-employment. When applied to the post 1999 period, this methodology reproduces fairly accurately the actual measure of weeks worked available (Needham, 2007).

Employment data from the LLMDB have two main shortcomings. First, the LLMDB does not currently contain employment spells dates, but it reports the number of employment spells recorded in a given year, so that it is possible to know how many jobs someone has held in a given year, with the associated weeks worked and pay, but it is not possible to know their start and end dates, nor their chronological order. This implies that the best measure of wages from this survey is the average weekly wage over a fiscal year. Also, this means that it is not possible to know whether the destination of a given unemployment spell is paid work, but it is possible to know whether and how much an individual worked in the fiscal year following an unemployment spell.

Second, the LLMDB does not provide information on weekly hours worked. This is mostly a drawback for the analysis of female employment and earnings, given that the incidence of part-time work among British women is fairly high during my sample period (around $42 \%$ according to the Labour Force Survey). Thus the empirical analysis will be restricted to males.

Figure 7 display raw data on employment and earnings from the LLMDB between 1978 and 2003. The average number of weeks worked in a year declined steadily in the sample period, while both annual and weekly earnings increased. Weekly earnings have been increasing at an average 
rate of $5.8 \%$ per year during the sample period, and this corresponds to an average $1.2 \%$ real growth. ${ }^{11}$ It is worthwhile to notice the blip in annual weeks worked in 1997-1998 and the dip in annual earnings in 1996. The apparent anomalies could be potentially explained by the fact that recording methods changed in 1997, and the LLMDB was moved on to a new National Insurance computerized system. The move from the old to the new system may in part explain the observed changes in variables of interest between 1996 and 1997.

\section{Methodology and preliminary evidence}

In order to assess the long-term effects of JSA exposure on postunemployment outcomes, one needs to take into account the retroactive nature of the reform, which applied to all unemployment claimant spells as of 7 October 1996, including those started during the previous UB/IS regime. In particular, this feature rules out major discontinuities in the relationship between the start date of an unemployment spell and future outcomes. I will thus compare outcomes for cohorts of unemployment entrants that are close enough in entry dates to be reasonably similar in aggregate factors, but far enough to have significantly different probabilities of being treated by the JSA.

For a treatment group I use claimant unemployment spells for males aged 16-64, started in the three months following JSA introduction, and more precisely between 7 October 1996 and 5 January 1997. All these spells are subject to the JSA rules. For a control group I use spells started six to three months before JSA introduction, that is between 8 April and 7 July $1996 .{ }^{12}$ These spells are initially not subject to JSA rules, but eventually become subject if they last beyond 7 October 1996. Thus the distinction between treatment and control is based on different intentions to treat.

There are a number of issues to be discussed to understand how good a control group this would be. First, individuals in the control group may become treated if they do not exit unemployment before 7 October 1996. Thus the most direct interpretation of the resulting estimates is the effect of being treated by JSA, as opposed to not being treated in first 3-6 months of unemployment. But further assumptions would be needed to allow for a more general interpretation of the estimates. For example, if the treatment probability were randomly distributed among individuals in the control group, conditional on observable characteristics, then the issue would be simply one of adequately re-scaling the obtained effect of JSA. For example, in my sample this probability happens to be almost exactly $50 \%$, and thus the coefficients obtained on these treatment and control groups should be multiplied by two.

\footnotetext{
${ }^{11}$ Using the retail price index from the Office for National Statistics.

${ }^{12}$ Note that the start date of my sample period, 8 April 1996, is also the date when entitlement for new UI recipients is halved from 12 to 6 months. Thus in this sample there are no differences in entitlement between the pre- and post-JSA period.
} 
But the probability of being treated in the control group depends on the timing of job finding, and this is in general affected by unobserved characteristics that define someone's employability, such as motivation, ability, search effort etc. If the less-employable are also the less able in the labor market, individuals who end up being treated in the control group have lower average unobserved ability. Thus, what matters for the direction of the associated bias is whether the JSA is going to have a stronger impact on post-unemployment earnings for the more or the less able workers. If the former is true, the estimated effect of the JSA obtained on these treatment and control groups overestimates the true effect, once scaling has been taken into account. If the latter is true, as it is plausible, one obtains an underestimate of the true effect. My estimates control for detailed past employment histories, which should act as a good proxy for a number of relevant unobservables (see also Card and Sullivan, 1988).

Second, I select control and treatment groups on the timing of job loss, and more precisely, on the timing of signing-on for unemployment benefits. One may worry about strategic behavior in the time of signing-on in the presence of anticipatory effects of JSA. And in principle individuals may try to alter the signing-on behavior in the face of JSA by (i) signing-on earlier than they would have done without the JSA; (ii) signing-on later; (iii) not signing-on at all. But how likely is this kind of strategic behavior prior to JSA introduction? It may be argued that trying to sign-on (shortly) earlier does not avoid treatment, as JSA is retroactive; signing-on later simply implies loss of unemployment income, thus is clearly not optimal; and finally not signing-on at all implies again loss of unemployment income: if one really dreads the prospect of the new JSA rules it is optimal to sign-on initially and possibly collect a few weeks' worth of benefits before being sanctioned.

Some indirect evidence on this can be grasped by looking at Figure 8, which gives the number of claimant unemployment spells started each week between 1 January 1996 and 31 December 1997. The pattern of the unemployment inflow is fairly smooth., and shows no sign of any unusual behavior in the unemployment inflow around the time of JSA introduction. Figure 9 provides a closer snapshot of daily inflow data for September and October 1996. This reveals a marked weekly pattern in starting dates, with Mondays being by far the busiest days, and the frequency of new spells declining monotonically during the week, but again there is no evidence of bunching of new spells shortly before or after 7 October.

It would be interesting to be able to observe the same kind of evidence in the unemployment outflow, but as already noted in Section 5 the LLMDB data are not ideal for this purpose, due to heavily bunched ending dates of IS spells, which produce sizeable spikes in the end dates of claimant unemployment spells, as shown in Figure 10. But official labor market data reported in Figure 1 show no unusual behavior in the unemployment outflow just before JSA introduction, with a strong increase immediately afterwards. 
Finally, treatment and control groups are certainly going to be different as far as seasonal factors are concerned. For this reason I construct treatment and control groups for the same dates in 1997 and 1998, and estimate the effect of JSA on future outcomes using a difference in differences strategy. ${ }^{13}$ I estimate an equation of the form

$$
y_{i}=\beta_{0}+\beta_{1} C_{i}^{96}+\beta_{2} C_{i}^{97}+\beta_{3} T_{i}+\beta_{4}\left(C_{i}^{96} * T_{i}\right)+\gamma X_{i}+\varepsilon_{i}
$$

where $y_{i}$ represents an outcome variable, $X_{i}$ is a vector of individual characteristics, $C_{i}^{96}$ and $C_{i}^{97}$ are dummy variables for the 1996 and 1997 cohorts, respectively, $T_{i}$ denotes treatment (or, equivalently, entry during quarter four), and the $C_{i}^{96} * T_{i}$ interaction picks the effect of JSA.

As the main underlying variation in treatment probabilities is defined at the level of the quarter of unemployment entry, standard errors need to be adjusted accordingly. With a small number of clusters (six in this case, including treatment and controls in three yearly entry cohorts), clustering at the group level can still deliver biased standard errors (Donald and Lang, 2007, and Cameron, Gelbach and Miller, 2008), and indeed standard errors clustered at the group level in estimating equation (7) were in several cases even lower than non-adjusted standard errors. While there is no obvious remedy for a problem of few clusters, I tried two alternatives. First, I cluster standard errors at the monthly level, as opposed to the quarterly level, thus using eighteen instead of six clusters. Second, I bootstrap $t$-statistics on the main coefficient of interest, allowing for clustering at either the monthly or the group level (see Cameron et al, 2008, Appendix). These procedures gave very similar results as far as the significance of the main effects of interest are concerned, and for simplicity all standard errors reported in what follows are those obtained by clustering at the monthly level.

Turning to identification, specification (7) is going to deliver an unbiased estimate for the coefficient of interest, $\beta_{4}$, if

$$
\begin{aligned}
& E\left(\varepsilon_{i} \mid C_{i}^{96}=1, T_{i}=1, X_{i}\right)-E\left(\varepsilon_{i} \mid C_{i}^{96}=1, T_{i}=0, X_{i}\right)= \\
& E\left(\varepsilon_{i} \mid C_{i}^{96}=0, T_{i}=1, X_{i}\right)-E\left(\varepsilon_{i} \mid C_{i}^{96}=0, T_{i}=0, X_{i}\right) .
\end{aligned}
$$

In other words, as treatment and control groups are selected on the basis of their date of job loss, the underlying identifying assumption is that the correlation between the timing of job loss and unobservables, if any, be the same across cohorts. This assumption is likely to be violated in two cases. First, it would not hold if seasonal patterns differ across the three years considered, but this does not seem to be the case because when I control for aggregate labor market tightness in the

\footnotetext{
${ }^{13}$ Strictly speaking, one extra cohort of unemployment entrants would be sufficient for this purpose. The use of two extra cohorts (1997 and 1998) has the advantage to help better pin down seasonal factors, and to increase the number of clusters to 6 (one treatment and one control group for each cohort), so as to improve computation of standard errors.
} 
month of unemployment entry the resulting estimates are hardly affected. Second, (8) would also not hold if there are reasons to expect strategic signing-on timing - but I have argued above that this is unlikely, and Figures 8 and 9 show no evidence of uncommon behavior in unemployment inflow rates around the time of JSA introduction. Also, indirect evidence on this can be gathered by observable pre-treatment characteristics of individuals in control and treatment groups in the two cohorts.

Descriptive statistics for treatment and control groups are reported in Table 1 and Figures 1114. Table 1 reports information on age, the current unemployment spell, and future benefit spells, separately for youths (16-24 years old) and adults (25-64 years old). There are about 8,500 spells in the youth sample and 16,400 in the adult sample. These groups are very similar in their age, but differ in the duration of their current spell and in its destination. The control group in the 1996 cohort tends to have longer spells than the other groups, and this is the main effect emphasized by the official evaluations of the JSA, although not with a difference in differences approach. This group also has a lower probability to experience new benefit spells in the near future.

More detailed information on earnings and weeks worked for treatment and control groups in different cohorts is presented in Figures 11 and 12, for the youth and the adult samples respectively. Panel A in Figure 11 gives the proportion of young men with positive earnings in each year for treatment and control groups in the three cohort. The relevant series are plotted for the period 1990 onwards, because the vast majority in this sample enters the labor force after 1990. The vertical line in correspondence of 1996 represents the introduction of JSA. This coincides with the reference unemployment spell for the 1996 cohort, while the reference unemployment spells for the 1997 and 1998 cohorts takes place one and two years later, respectively. Overall, the fraction of men with positive earnings rises for all groups by about 50 percentage points during the 6 years prior to JSA treatment, and this is clearly an age effect, reflecting labor market entry of this relatively young cohort. After the reference unemployment shock, the trend in such fraction flattens out or even declines. It is also worthwhile to notice that the proportion with positive earnings has a spike in the year of job loss, simply telling that the reference unemployment spell tends to follow in most cases a period of paid employment. The pre-shock trends are identical for treatment and control groups, and if anything the level of the proportion of those in paid work is slightly higher for the control than the treatment. Panel B plots average annual earnings, including zero values for those not in work, and shows again an identical upward trend in earnings in the pre-shock period. Panel C presents a very similar picture for annual weeks worked (including zero values for non-participants), and again Panel D for log weekly earnings. Figure 12 plots the corresponding trends for the adult sample, starting in 1985. The main differences with respect to the younger sample are, as expected, a higher levels of earnings, and also the absence of strong upward pre-shock trends. 
An interesting feature that stands out from Figures 11 and 12 is that pre-treatment trends are in general very close for treatment and control groups for the three cohorts. More importantly, the associated difference in differences between the 1996 cohort on the one hand and the later cohorts on the other hand is not significantly different from zero for any of the variables considered in the pre-treatment period. Figures 13 and 14 plot the difference in differences for the same variables represented in Figures 11 and 12, where year 0 corresponds to 1996, 1997 and 1998 for the three cohorts respectively. In Panel A a probit version of equation (7) is estimated, with no $X$ variables included, while Panels B-D are based on OLS. The solid lines represent the point estimates for $\beta_{4}$ (and, specifically, marginal effects in Panel A), and the dashed lines represent the $90 \%$ and 95\% confidence intervals, showing that, for the four labor market indicators considered, all point estimates lie within the $90 \%$ interval in the pre-treatment period, except in one instance only (the difference in weekly wages for adults three years before the reference unemployment spell). Recall that in order to consistently estimate $\beta_{4}$ one needs that any difference in unobservables between the treatment and control groups be the same across the two cohorts. Using work histories as a proxy for individual unobservables, the evidence presented in Figures 13 and 14 is in line with my identifying assumption.

It should finally be noted that some of the trends in Figures 11 and 12 seem to diverge after JSA introduction, and in some cases more for the 1996 than the later cohorts, as also shown by point estimates in Figures 13 and 14 for the post-treatment period. This is indicative of potential JSA effects on future outcomes. The next section will provide more detailed results on post-treatment effects, controlling for age of respondents and pre-treatment trends.

\section{Results}

\subsection{Employment and earnings}

I start by presenting evidence on the effects of JSA on the probability of leaving the unemployment claimant register. Not only was this the main effect emphasized by the official evaluations of the JSA, but also it could be the main channel through which one can expect more long-term effects.

I thus estimate a duration model of exit from unemployment, using a specification analogous to (7), except that the duration model is non-linear. The results of the Cox proportional hazard model are presented in Panel A of Table 2, where the coefficients reported refer again to the interaction term between the 1996 cohort and treatment. All specifications also include separate dummy variables for treatment and the 1996 and 1997 cohorts. The standard errors are clustered at the monthly inflow level.

The first two columns in the Table refer to the young sample, and the next two to the adult sample. The regression of column 1 only controls for treatment and yearly cohorts as extra re- 
gressors, and shows evidence of a $11.4 \%$ increase in the unemployment exit hazard for the young. Column 2 also controls for age, age squared, and past employment history (i.e. the total number of weeks worked and annual earnings in each of the previous three years and their square). ${ }^{14}$ As expected from the evidence presented in Table 1 and Figure 11, the inclusion of further covariates hardly affects the results. The next two columns show very similar results for the adults. Recall that the control group here includes about $50 \%$ of treated individuals, and thus a simple rescaling of these estimates would predict a reduction in unemployment duration over $20 \%$, corresponding to about 6-8 weeks, across age groups and specifications.

However, as information on ending dates of spells is heavily bunched at quarterly frequencies, a continuous time duration model is not the best way to describe unemployment exit. Another way to look at the effect of JSA on the outflow from the unemployment register consists in comparing the fraction of individuals in each group who were no longer claiming after three or six months since unemployment entry. Interestingly, three and six months correspond almost exactly to the median and mean unemployment duration in this sample, respectively. Panel B shows a marginal effect of JSA of about $15 \%$ on the probability to exit within three months for youths, and about $9 \%$ for adults. The effects on the six months' exit rate, reported in Panel C, are substantially lower. This is to be expected because the new JSA rules kick in at the beginning of an unemployment spell, and thus this is when they are more likely to make a difference to exit rates.

Table 2 thus replicates the main result of the JSA evaluation literature, namely its strong and significant impact on the exit rate from unemployment. But moving claimants off benefits may not be equivalent to moving them on to new jobs. The LLMDB does not allow me to fully characterize unemployment destinations, because it does not contain information on starting dates of employment spells, but I can use information on weeks worked and earnings for the fiscal year after treatment (and for later years) in order to assess the impact of JSA on both employment and post-unemployment earnings.

Figure 15 present estimates of the effect of JSA on post-unemployment outcomes for the young. These estimates are analogous to the post-treatment estimates presented in Figure 13, but unlike in Figure 13 they control for observable characteristics, including the pre-treatment trends.

Panel A shows that the effect of JSA on the probability of having positive earnings in the five years after the reference unemployment spell. Estimates provided for year zero are hard to interpret because, given yearly information on employment and earnings, may reflect both pretreatment and post-treatment effects. Specifically, earnings in the 1996 fiscal year for someone who has an unemployment spell in 1996 may include both pre-unemployment and post-unemployment earnings. This of course cannot happen from year 1 onwards. JSA implied a reduction of $5.4 \%$ in

\footnotetext{
${ }^{14}$ Extending employment and earnings histories 10 instead of 3 years back produced virtually identical results.
} 
the probability of positive earnings in the year after the shock for young workers, and this effect is statistically significant at the $1 \%$ level. The JSA effect falls to $3.7 \%$ in the next year, and becomes not significantly different from zero from year four. Registering for unemployment benefits soon after JSA introduction, as opposed to six months earlier, implies thus a significant fall in the future employment probability for the young, with fairly long-lived effects.

Estimates for the effect on the average level of earnings is presented in Panel B. Estimates are negative from year 1 onwards, and reach a peak of about $-900 £$ in year 4 . They then become non significantly different from zero (at the $5 \%$ level) in year 5 . The negative impact on average earnings tends to reflect both a negative impact on the probability to work (see Panel A), and an effect on earnings, conditional on employment. This latter effect is also negative between year 1 and year 4 (estimates not reported), but is not precisely estimated.

The effect of JSA on weeks worked, reported in Panel C, tends to be negative and significant in year one, and similarly as for previous outcomes it tails off in the next four years. Finally, Panel D reports estimates of the effect of the JSA on ( $\log )$ weekly earnings for those with positive earnings, and these tend to be closer to zero and not significant initially, but become significant in years 3-5 after the job loss. It is probably hard to reconcile such late decline in weekly earnings with the direct impact of JSA, because if anything one would expect an immediate effect in the first year after the reference unemployment spell, which is gradually reabsorbed as individuals who are initially mismatched search on-the-job for better matches. Some explanation of this behavior may be related to the employment selection effects of JSA. Panel A has shown that the JSA had an important initial impact on the proportion of individuals in work, which fades gradually over the next five years, as the treated catch up with the non-treated in their employment levels. Thus the employment stock may be of relatively high quality among the treated initially, because only the most able have initially found work, and then quality declines as the less-able among the treated find work. This selection mechanism may help explain why one does not find a JSA effect initially, but finds instead a negative effect in the following years. ${ }^{15}$

Figure 16 reports relevant results for the adults. In general, the associated estimates are smaller in magnitude and less precise than for youths. Specifically, initial effects are similar to those estimated for youths, but beyond 2 years after an unemployment shock very few effects are significant for adults re-employment outcomes.

In summary, effects of JSA on this sample include a reduction in the probability to have positive earnings after an unemployment shock, with negative effects on total earnings and weeks worked, and more moderate and less precise effects on weekly earnings. These effects are consistent with

\footnotetext{
${ }^{15}$ Another potential explanation, also based on selection mechanisms, could be that more able youths would take some time out of the labor force to go back into education or Government training programmes. But no evidence on this can be gathered from these data.
} 
moderate changes in reservation wages, but large changes in the composition of nonemployment and overall labor market attachment. This is what would be predicted by a search model in which the rise in job search requirements is relatively more important than the expected income loss from dropping out of the unemployment register, as it could have well been the case for the JSA introduction.

Finally, all effects reported tend to be stronger and more precisely estimated for the younger sample. One explanation could be that for youths eligible for UB, JSA introduction meant both an increase in search requirements, and a reduction in the benefit level, with amplified effects on postunemployment outcomes. But as argued in Section 3 this explanation is unlikely, as the proportion of individuals eligible for UB only represents a minority of observations. The other explanation is that the effects of search requirements alone may be heterogeneous and stronger for the youths. The UK Government's concern about poor re-employment prospects for young unemployed was indeed behind the introduction of the New Deal for Young People in April 1998, which combined JSA search requirements with intensive help with job search (see Blundell, Costa Dias, Meghir and Van Reenen, 2004).

\subsection{Future benefit spells}

Previous estimates show that the JSA raised the unemployment outflow, but at the same time also raised the probability of not working at all in the following year, so one may wonder what happens to individuals who leave the unemployment register but do not get long-lasting jobs. One possibility is that they may experience new claimant unemployment spells, or apply for and obtain other benefits, which are not conditional on active job search.

To answer this question I use information on different types of benefit spells contained in the LLMDB. The UK welfare system, like most systems, includes several types of benefits, that can be related to job search, income, health, work etc. For example, during the six months preceding JSA introduction, between 8 April and 6 October 1996, the LLMDB registers about 45,000 new benefit spells for individuals aged 16-64. The most important category among these is represented by unemployment benefits, which account for about $80 \%$ of total spells starting in this time span. The next category is represented by health-related benefits, including Incapacity Benefits and the Disability Living Allowance. IB can be claimed by individuals who are unable to work because of ill health or a disability, and accounts for about $9 \%$ of benefit spells in the pre-JSA period. The DLA is a benefit for individuals who need personal care due to mental or physical disabilities, and accounts for $4 \%$ of spells. Finally come in-work benefits, represented by the Working Family Tax Credit, which includes about $5 \%$ of benefit spells. One year later, that is between 8 April and 6 October 1997, the LLMDB registers about 28,000 new benefit spells. The importance of unemployment 
benefits has declined to about $70 \%$, and that of health-related benefits has increased to $14 \%$ for IB, and to $6 \%$ for DLA. In-work benefits have also risen to $9 \%$.

To look at the impact of the JSA on unemployment exits into other benefits, I estimate a probit version of equation (7), where the dependent variable is equal to 1 if an individual is receiving benefits of a given type within 3 or 6 months of the end of the reference unemployment spell, and zero otherwise. Benefit types considered here are unemployment benefits (whether on UB/IS in the old regime or JSA in the new regime), and IB. Destinations into other benefit categories represent a very small minority of this sample, and the corresponding estimates were always very close to zero and thus not reported.

The results are reported in Table 3. All estimates for other benefit destinations are positive and in several cases significantly different from zero. In general the estimated effects tend to be slightly larger and more precisely estimated when one looks at transitions within six, rather than three months. Both youths and adults are about $3 \%$ more likely to experience new claimant unemployment spells under the new JSA regime, though this effect only reaches standard significance levels for the adults. Both groups are also more likely to start spells of IB, and the associated effect is significant for both groups and slightly stronger for the adults.

The estimated impact of JSA on the take-up rate of IB is noteworthy for two reasons. First, this impact is quite large in magnitude. For example: the associated point estimate is about $2.5 \%$ for youths, and a simple rescaling of this coefficient due to $50 \%$ of treatment in control group would imply an impact of nearly 5\%. This is a very large figure if compared to the baseline $5 \%$ transitions into IB for the young in the 1996 control group (see Table 1). For the adults, the estimated effect is slightly stronger (about $6 \%$ if one rescales the obtained point estimate), and also the associate baseline take-up rate of IB is slightly higher at about $9 \%$. This piece of evidence fits in the rising trend in take-up rates of IB in the UK, and is consistent with the widespread view that individuals who had lowest re-employment rates were informally advised by the Employment Service to apply for IB (see Nickell and Quintini, 2002).

Second, while the impact of the new JSA rules on the average number of weeks spent on benefits would imply a reduction in benefit expenditure, the take-up rate of new benefits following the reference unemployment spell makes conclusions on total benefit expenditure more problematic. One can attempt a very crude back-of-envelope calculation of the impact of JSA on total benefit expenditure by combining the estimates presented above with data on weekly benefit payments and their average duration. ${ }^{16}$ Table 1 shows a reduction in unemployment duration by about $11 \%$, roughly corresponding to 6 weeks once rescaling is taken into account. This implies savings of about $295 £$ per person treated by JSA. However, Table 3 shows that this person is $5-6 \%$ more likely to

\footnotetext{
${ }^{16}$ Needless to say, this is not supposed to be indicative of the JSA's effects on overall welfare.
} 
start a spell on IB shortly after completion of a JSA-covered unemployment spell. Average IB duration in the post-JSA period is about 49 weeks, and weekly benefits in 1996/97 were $£ 46.15$ for the first 28 weeks, and then increased to $£ 54.55$ from week 29 onwards. These figures thus imply an expected IB cost of about $£ 134$ per person treated, which erodes about $45 \%$ of the initial benefit savings. If on top of this one takes into account that individuals treated are also more likely to start a new unemployment spell within six months of completing their current spell, net savings on benefits per person treated fall further to $£ 55$.

\subsection{Robustness tests}

The adopted definition of control and treatment groups, as well as some features of the data, require a number of robustness checks. First, as noted in Figure 9, the unemployment inflow frequency has a marked weekly pattern, and this may reflect the timing of initial benefit payments, rather than the date a job loser initially approached the Employment Service. I thus converted the benefit spells data from daily into weekly, by moving each start date to the previous and following Mondays in turn, and constructed treatment and control groups in the same way as explained in Section 6. The estimates obtained on this new sample were virtually identical to those obtained on the original one.

Second, as treatment and control groups are selected according to their date of job loss for three consecutive years, one may worry about interactions between seasonal factors and year effects. For example, if the labor market were in general tighter in the fall (when the treatment is selected) than in the spring (when the control is selected), and this effect were stronger in 1997 than in 1996, one could potentially predict poorer lower relative re-employment prospects for the treatment group in 1996 as a consequence of macroeconomic effects. Evidence on macroeconomic effects can be provided by the monthly vacancy to unemployment ratio, which is typically used as a measure of labor market tightness. This ratio increases roughly monotonically in Britain between January 1996 and December 1998, and thus shows no evidence of different seasonal patterns in 1996, 1997 and 1998. As a final check, I repeated the main estimates controlling for the value of labor market tightness in the month of job loss, and the results stayed largely unchanged.

Third, I run a falsification test, based on treatment and control groups for 1997, 1998 and 1999, constructed in the same way as I previously did for 1996, 1997 and 1998. If my previous estimates identify the effect of JSA, one should obtain no significant effects of an interaction term between the treatment and the 1997 cohort on this new sample, for any of the post-unemployment outcomes considered. This is indeed what I obtain, as shown in Table 4 for exits into other benefit spells, and in Figures 17 and 18 for post-unemployment earnings and weeks worked.

Finally, I follow a slightly different estimation strategy from the DID strategy used above. As 
already mentioned, a potential drawback of my DID strategy is that JSA coverage in the control group is not zero, because treatment and control are selected on the basis of a spell start date. This problem would not exist if one selected them based on a spell end date, except that the treatment dummy would be endogenous with respect to individual characteristics. A possible solution consists in estimating the effect of treatment (i.e. terminating an unemployment spell on or after 7 October 1996) on post-unemployment outcomes, having instrumented the probability if treatment by entry date, and controlled for seasonality using later entry cohorts. I thus select all unemployment benefit spells started between April 1996 and March 1999, corresponding to the full 1996-1998 fiscal years, and estimate an equation of the form:

$$
y_{i}=\beta_{0}+\beta_{1} C_{i}^{96}+\beta_{2} C_{i}^{97}+\sum_{j=1}^{3} \beta_{3 j} Q_{i j}+\beta_{4} J S A_{i}+\gamma X_{i}+\varepsilon_{i}
$$

where $C_{i}^{96}$ and $C_{i}^{97}$ refer to entry cohorts, $Q_{i j}$ is quarter of entry, and $J S A=1$ for spells ended on or after 7 October 1996 and zero otherwise. The $J S A$ variable is in turn instrumented by the distance between fall 1996 and the calendar quarter of entry. In particular, I create a variable $z$ equal to $\min \left(\right.$ Fall 1996 - calendar quarter of entry,0), and then use $z$ and $z^{2}$ as instruments for $J S A$.

The identification strategy here is conceptually similar to that of the rest of the paper, namely that seasonal factors be constant across entry cohorts. However, the different sampling of entry cohorts and different construction of the treatment variable should provide a robustness check for estimates presented above. The results obtained are quite similar to those obtained using DID estimates. In particular, JSA treatment raises the probability to start an IB spell by around $4 \%$ (see bottom panel in Table 5). It reduces the probability of having positive earnings in the year after the shock for both the young and the adult samples by about 5\% (see Panel A in Figures 19 and 20), and again has a negative impact on annual earnings, which is stronger for the young than for the adult sample (see Panel B in Figures 19 and 20). Note that these estimates do not need to be rescaled, given the different definition of treatment from the DID case, and thus imply an overall weaker effect of JSA on postunemployment outcomes than estimates based on DID.

\section{Conclusions}

This paper has investigated the post-unemployment effects of higher job search requirements, exploiting variation provided by the introduction of the UK JSA in October 1996. In a simple job search framework, one expects that tighter requirements for UI eligibility lower the reservation wage and thus the quality of post-unemployment jobs, and raises the fraction of nonclaimant nonemployed, with consequences on labor market attachment and job search effort. 
Using administrative longitudinal data on spells on unemployment benefits and earnings, I find that JSA has had a positive and significant impact on the claimant unemployment exit rate, as well as on exits into other benefits, and a negative and significant impact on the probability of working for up to four years following an unemployment spell. Starting a spell soon after JSA introduction, as opposed to six months earlier, raises the likelihood of a spell on Incapacity Benefits by about $2.5-3 \%$, and lowers the likelihood of positive earnings by about $4-5 \%$, together with the level of earnings and the number of weeks worked. Weekly earnings (conditional on work) also seem to be lower for the treated individuals, but the confidence intervals around these estimated effects are quite large to exclude a wider variety of scenarios. Overall, all the estimated effects tend to be stronger for the 16-24 than the 25-64 year old sample.

A possible interpretation is that tighter search requirements implied by the JSA indeed moved claimants off unemployment benefits, without really raising job finding rates. Among claimants treated by the JSA, those who found jobs quickly did not see their fortunes much changed with respect to the previous regime, as implied by the absence of significant effects on weekly earnings in the year following job loss. But those who left the unemployment register without finding a job might have in general become detached from the labor market - for example by no longer perceiving themselves as "workers", as they were no covered by labor force welfare - and in particular were more likely to start spells on benefits that were not search related, with detrimental effects on their search effort and fairly long-lasting effects on their employment rates. This was reflected in a net loss in (unconditional) weeks worked and earnings with respect to the previous system during about three years after a job loss.

\section{References}

[1] Acemoglu, D. (2001), "Good Jobs versus Bad Jobs", Journal of Labor Economics 19: 1-21.

[2] Acemoglu, D. and R. Shimer (1999), "Efficient Unemployment Insurance", Journal of Political Economy 107: 893-928.

[3] Acemoglu, D. and R. Shimer (2000), "Productivity Gains from Unemployment Insurance", European Economic Review 44: 1195-1224.

[4] Addison, J. and M. Blackburn (2000), "The Effects of Unemployment Insurance on Postunemployment Earnings", Labour Economics 7: 21-53.

[5] Atkinson, A and J. Micklewright (1991), "Unemployment Compensation and Labor Market Transitions: A Critical Review", Journal of Economic Literature 29: 1679-1727.

[6] Ashenfelter, O., D. Ashmore and O. Deschenes (1999), "Do Unemployment Insurance Recipients Actively Seek Work? Randomized Trials in Four US States". NBER Working Paper 6982. 
[7] Autor, D. and M. Duggan (2003), "The Rise in the Disability Rolls and the Decline in Unemployment", Quarterly Journal of Economics 118: 157-205.

[8] Autor, D. and M. Duggan (2006), "The Growth in the Social Security Disability Rolls: A Fiscal Crisis Unfolding", Journal of Economic Perspectives 20: 71-96..

[9] Belzil, C. (2001), "Unemployment Insurance and Subsequent Job Duration: Job Matching versus Unobserved Heterogeneity". Journal of Applied Econometrics 16: 619-636.

[10] Blundell, R., M. Costa Dias, C. Meghir and J. Van Reenen (2004), "Evaluating the Employment Impact of a Mandatory Job Search Program", Journal of the European Economic Association 2: 569-606.

[11] Burgess, P. and J. Kingston (1976), "The Impact of Unemployment Insurance Benefits on Reemployment Success" Industrial and Labour Relations Review 30: 25-31.

[12] Cameron, C., J. Gelbach and D. Miller (2008), "Bootstrap-Based Improvements for Inference with Clustered Errors". Review of Economics and Statistics 90: 414-427.

[13] Card, D., R. Chetty and A. Weber (2007a), "Cash-on-Hand and Competing Models of Intertemporal Behavior: New Evidence from the Labor Market". Quarterly Journal of Economics 122:1511-1560.

[14] Card, D., R. Chetty and A. Weber (2007b), "The Spike at Benefit Exhaustion: Leaving the Unemployment System or Starting a New Job?". American Economic Review Papers and Proceedings 97: 113-118.

[15] Card, D. and D. Sullivan (1988), "Measuring the Effect of Subsidized Training Programs on Movements In and Out of Employment". Econometrica 56: 497-530.

[16] Centeno, M. (2004), "The Match Quality Gains from Unemployment Insurance", Journal of Human Resources 39: 839-863.

[17] Classen, K. (1977), "The Effect of Unemployment Insurance on the Duration of Unemployment and Subsequent Earnings". Industrial and Labour Relations Review 30: 438-50.

[18] Department for Social Development (1999), Jobseeker's Allowance Summary Statistics, http://www.dsdni.gov.uk/jsa_nov_1999.pdf.

[19] Diamond, P. (1981), "Mobility Costs, Frictional Unemployment and Efficiency", Journal of Political Economy 89: 798-812.

[20] Dolton, P. and D. O'Neill (1996), "Unemployment Duration and the Restart Effect: Some Experimental Evidence", Economic Journal 106: 387-400.

[21] Dolton, P. and D. O'Neill (2002), “The Long-Run Effects of Unemployment Monitoring and Work-Search Programs: Experimental Evidence from the United Kingdom", Journal of Labor Economics: 20, 381-403.

[22] Donald, S. and K. Lang (2007), "Inference with Difference-In-Differences and Other Panel Data". The Review of Economics and Statistics 89: 221-233. 
[23] Ehrenberg, R. and R. Oaxaca (1976), "Unemployment Insurance, Duration of Unemployment and Subsequent Wage Gain", American Economic Review 66: 754-766.

[24] Faggio, G. and S, Nickell (2004), "The Rise in Inactivity among Adult Men", in R. Dickens, P. Gregg and J. Wadsworth (eds.) The Labour Market Under New Labour: The State of Working Britain, London, Palgrave Macmillan.

[25] Finn, D., I. Murray and C. Donnelly (1996), Unemployment and Training Rights Handbook, London: The Unemployment Unit.

[26] Fredriksson and Holmlund (2006), "Improving Incentives in Unemployment Insurance", Journal of Economic Surveys 20: 357-386.

[27] Holen, A. (1977), "Effects of Unemployment Insurance Entitlement on Duration and Job Search Outcome". Industrial and Labor Relations Review 30: 445-450.

[28] Johnson, T. and D. Klepinger (1994), "Experimental Evidence on Unemployment Insurance Work-Search Policies", Journal of Human Resources 29: 695-717.

[29] Juraida, Š. (2002), "Estimating the Effect of Unemployment Insurance Compensation on the Labor Market Histories of Displaced Workers". Journal of Econometrics 108: 227-252.

[30] Krueger, A. and B. Meyer (2002). "Labor Supply Effects of Social Insurance." in A. Auerbach and M. Feldstein, eds. Handbook of Public Economics Vol 4. North-Holland: Amsterdam.

[31] Krueger, A. and A. Mueller (2008), "Job Search and Unemployment Insurance: New Evidence from Time Use Data", mimeo, Princeton University.

[32] Lalive, R., J. van Ours and J. Zweimüller (2007), "How Changes in Financial Incentives Affect the Duration of Unemployment", Review of Economic Studies 73: 1009-1038.

[33] Manning, A. (2005), "You Can't Always Get What You Want: The Impact of the UK Jobseekers' Allowance". CEP Discussion Paper 697.

[34] Marimon, R. and F. Zilibotti (1999), "Unemployment Vs. Mismatch of Talents: Reconsidering Unemployment Benefits", Economic Journal 109: 266-291.

[35] McVicar (2008), "Job Search Monitoring Intensity, Unemployment Exit and Job Entry: Quasiexperimental evidence from the UK", Labour Economics, forthcoming.

[36] Meyer, B. (1995), "Lessons from the U.S. Unemployment Insurance Experiments", Journal of Economic Literature 33: 91-131

[37] Mortensen, D. (1986), "Job Search and Labor Market Analysis" in Ashenfelter, O. and R. Layard (eds.) Handbook of Labor Economics, Volume 2, Amsterdam: North-Holland, pages 849-919.

[38] Needham, A. (2007), "Final Methodology for the Calculation of Class 1 Employee's Weeks Worked". Mimeo, Department for Work and Pensions.

[39] Nickell, S. and G. Quintini (2002), "The Recent Performance of the UK Labour Market", Oxford Review of Economic Policy 18: 202-220. 
[40] van Ours, J. and M. Vodopivec (2006), "Does Reducing Unemployment Insurance Generosity Reduce Job Match Quality?". Journal of Public Economics 92: 684-695.

[41] Paserman, D. (2007), "Job Search and Hyperbolic Dicounting: Structural Estimation and Policy Evaluation". Economic Journal 118: 1418-1452.

[42] Pointer, R and M. Barnes (1997), Jobseeker's Allowance Handbook, London: Child Poverty Action Group.

[43] Rayner, E., S. Shah, R. White, L. Dawes and K. Tinsley (2000), "Evaluating Jobseeker's Allowance: A Summary of the Research Findings", Department of Social Security, Research Report No. 116.

[44] Smith, A., R. Youngs., K. Ashworth, S. McKay, R. Walker, with P. Elias and A. McKnight (2000), "Understanding the Impact of Jobseeker's Allowance", Department of Social Security, Research Report No. 111. 
Table 1

Characteristics of treatment and control groups

\begin{tabular}{|c|c|c|c|c|c|c|c|c|}
\hline \multirow[b]{3}{*}{1996 cohort } & \multicolumn{4}{|c|}{ Youths 16-24 } & \multicolumn{4}{|c|}{ Adults 25-64 } \\
\hline & \multicolumn{2}{|c|}{ Control } & \multicolumn{2}{|c|}{ Treatment } & \multicolumn{2}{|c|}{ Control } & \multicolumn{2}{|c|}{ Treatment } \\
\hline & Mean & St.d. & Mean & St.d. & Mean & St.d. & Mean & St.d. \\
\hline Age & 21.1 & 2.2 & 21.2 & 2.2 & 38.7 & 10.5 & 39.1 & 10.3 \\
\hline Duration of current spell days & 185.0 & 246.4 & 165.6 & 216.9 & 220.9 & 360.0 & 189.0 & 317.5 \\
\hline \multicolumn{9}{|l|}{ Within 6 month of completion: } \\
\hline$\%$ on new unemployment spell & 42.7 & & 47.2 & & 34.2 & & 37.3 & \\
\hline$\%$ on incapacity benefits spell & 5.0 & & 7.0 & & 9.1 & & 10.9 & \\
\hline Number of spells & \multicolumn{2}{|c|}{1515} & \multicolumn{2}{|c|}{1433} & \multicolumn{2}{|c|}{2509} & \multicolumn{2}{|c|}{2901} \\
\hline 1997 and 1998 cohorts & Mean & St.d. & Mean & St.d. & Mean & St.d. & Mean & St.d. \\
\hline Age & 21.0 & 2.3 & 21.0 & 2.2 & 38.6 & 10.3 & 38.8 & 10.3 \\
\hline Duration of current spell days & 132.2 & 180.4 & 133.4 & 163.9 & 196.3 & 306.0 & 189.0 & 287.1 \\
\hline \multicolumn{9}{|l|}{ Within 6 month of completion: } \\
\hline$\%$ on new unemployment spell & 49.1 & & 50.4 & & 37.8 & & 37.9 & \\
\hline$\%$ on incapacity benefits spell & 7.7 & & 7.7 & & 12.0 & & 10.9 & \\
\hline Number of spells & \multicolumn{2}{|c|}{2770} & \multicolumn{2}{|c|}{2816} & \multicolumn{2}{|c|}{5189} & \multicolumn{2}{|c|}{5777} \\
\hline
\end{tabular}

Source: LLMDB.

Table 2

Impact of JSA on claimant outflow

\begin{tabular}{|c|c|c|c|c|}
\hline \multicolumn{5}{|c|}{ Panel A: Cox proportional hazard model } \\
\hline & \multicolumn{2}{|c|}{ Youths (16-24) } & \multicolumn{2}{|c|}{ Adults (25-64) } \\
\hline JSA & $0.114^{* *}$ & $0.112^{* *}$ & $0.113^{* * *}$ & $0.124^{* * *}$ \\
\hline (s.e) & $(0.046)$ & $(0.046)$ & $(0.033)$ & $(0.034)$ \\
\hline Observations & 8450 & 8450 & 16202 & 16200 \\
\hline Other controls & No & Yes & No & Yes \\
\hline \multicolumn{5}{|c|}{ Panel B: Whether completed a spell within 3 months } \\
\hline & \multicolumn{2}{|c|}{ Youths (16-24) } & \multicolumn{2}{|c|}{ Adults $(25-64)$} \\
\hline JSA & $0.148^{* * *}$ & $0.151^{* * *}$ & $0.091^{* * *}$ & $0.095^{* * * *}$ \\
\hline (s.e) & $(0.022)$ & $(0.022)$ & $(0.017)$ & $(0.017)$ \\
\hline Observations & 8532 & 8532 & 16350 & 16348 \\
\hline Other controls & No & Yes & No & Yes \\
\hline \multicolumn{5}{|c|}{ Panel C: Whether completed a spell within 6 months } \\
\hline & \multicolumn{2}{|c|}{ Youths (16-24) } & \multicolumn{2}{|c|}{ Adults (25-64) } \\
\hline$\overline{\text { JSA }}$ & $0.042^{* *}$ & $0.041^{* *}$ & $0.071^{* * * *}$ & $0.074^{* * *}$ \\
\hline (s.e) & $(0.019)$ & $(0.019)$ & $(0.014)$ & $(0.014)$ \\
\hline Observations & 8532 & 8532 & 16350 & 16348 \\
\hline Other controls & No & Yes & No & Yes \\
\hline
\end{tabular}

Notes. Estimation methods: Cox proportional hazard model in Panel A and probit model in Panels B and C (marginal effects reported). $\mathrm{JSA}=\mathrm{C}^{96} * \mathrm{~T}$ (see equation (7)), and regressions also control for $\mathrm{T}, \mathrm{C}^{96}$ and $\mathrm{C}^{97}$ separately. Other controls included are: age, age squared, total weeks worked in each of the previous 3 years and their square, total earnings in each of the previous 3 years and their square. Standard errors are clustered at the monthly inflow level and reported in brackets. ${ }^{* * * * *},{ }^{* *}$ and ${ }^{*}$ denote significance at the $1 \%, 5 \%$ and $10 \%$ levels, respectively. 
Table 3

The impact of JSA on exit into other benefit spells

\begin{tabular}{|c|c|c|c|c|}
\hline \multicolumn{5}{|c|}{ New claimant unemployment spell within 3 months } \\
\hline & \multicolumn{2}{|c|}{ Youths $(16-24)$} & \multicolumn{2}{|c|}{ Adults (25-64) } \\
\hline JSA & 0.024 & 0.024 & $0.031 * *$ & $0.030 * *$ \\
\hline (s.e) & $(0.022)$ & $(0.022)$ & $(0.015)$ & $(0.015)$ \\
\hline Observations & 8532 & 8532 & 16350 & 16348 \\
\hline Other controls & No & Yes & No & Yes \\
\hline \multicolumn{5}{|c|}{ Spell of Incapacity Benefits within 3 months } \\
\hline & \multicolumn{2}{|c|}{ Youths $(16-24)$} & \multicolumn{2}{|c|}{ Adults (25-64) } \\
\hline JSA & $0.020 *$ & $0.020^{*}$ & $0.025 * *$ & $0.022 * *$ \\
\hline (s.e) & $(0.013)$ & $(0.012)$ & $(0.011)$ & $(0.011)$ \\
\hline Observations & 8532 & 8532 & 16350 & 16348 \\
\hline Other controls & No & Yes & No & Yes \\
\hline \multicolumn{5}{|c|}{ New claimant unemployment spell within 6 months } \\
\hline & \multicolumn{2}{|c|}{ Youths $(16-24)$} & \multicolumn{2}{|c|}{ Adults (25-64) } \\
\hline JSA & 0.034 & 0.035 & $0.029 *$ & $0.028^{*}$ \\
\hline (s.e) & $(0.023)$ & $(0.023)$ & $(0.016)$ & $(0.016)$ \\
\hline Observations & 8532 & 8532 & 16350 & 16348 \\
\hline Other controls & No & Yes & No & yes \\
\hline \multicolumn{5}{|c|}{ Spell of Incapacity Benefits within 6 months } \\
\hline & \multicolumn{2}{|c|}{ Youths $(16-24)$} & \multicolumn{2}{|c|}{ Adults (25-64) } \\
\hline JSA & $0.025^{*}$ & $0.024^{*}$ & $0.032 * * *$ & $0.029 * *$ \\
\hline (s.e) & $(0.014)$ & $(0.014)$ & $(0.012)$ & $(0.012)$ \\
\hline Observations & 8532 & 8532 & 16350 & 16348 \\
\hline Other controls & No & Yes & No & Yes \\
\hline
\end{tabular}

Notes. The outcome variable is 1 if a new benefit spell has started within 3 or 6 months since the end of the current spell. Estimation method: probit (marginal effects are reported). $\mathrm{JSA}=\mathrm{C}^{96} * \mathrm{~T}$ (see equation (7)), and regressions also control for $\mathrm{T}, \mathrm{C}^{96}$ and $\mathrm{C}^{97}$ separately. Other controls included are: age, age squared, total weeks worked in each of the previous 3 years and their square, total earnings in each of the previous 3 years and their square. Standard errors are clustered at the monthly inflow level and reported in brackets. ${ }^{* * *},{ }^{* *}$ and ${ }^{*}$ denote significance at the $1 \%, 5 \%$ and $10 \%$ levels, respectively. 
Table 4

The impact of JSA on exit into other benefit spells

Falsification test on 1997, 1998 and 1999cohorts

\begin{tabular}{|c|c|c|c|c|}
\hline \multicolumn{5}{|c|}{ New claimant unemployment spell within 3 months } \\
\hline & \multicolumn{2}{|c|}{ Youths $(16-24)$} & \multicolumn{2}{|c|}{ Adults (25-64) } \\
\hline JSA & 0.015 & 0.012 & 0.004 & 0.001 \\
\hline (s.e) & $(0.022)$ & $(0.022)$ & $(0.014)$ & $(0.014)$ \\
\hline Observations & 8531 & 8531 & 16182 & 16179 \\
\hline Other controls & No & Yes & No & Yes \\
\hline \multicolumn{5}{|c|}{ Spell of Incapacity Benefits within 3 months } \\
\hline & \multicolumn{2}{|c|}{ Youths $(16-24)$} & \multicolumn{2}{|c|}{ Adults (25-64) } \\
\hline JSA & -0.010 & -0.011 & 0.007 & 0.005 \\
\hline (s.e) & $(0.010)$ & $(0.010)$ & $(0.010)$ & $(0.009)$ \\
\hline Observations & 8531 & 8531 & 16182 & 16179 \\
\hline Other controls & No & Yes & No & Yes \\
\hline \multicolumn{5}{|c|}{ New claimant unemployment spell within 6 months } \\
\hline & \multicolumn{2}{|c|}{ Youths $(16-24)$} & \multicolumn{2}{|c|}{ Adults $(25-64)$} \\
\hline JSA & 0.011 & 0.008 & 0.015 & 0.012 \\
\hline (s.e) & $(0.023)$ & $(0.023)$ & $(0.016)$ & $(0.016)$ \\
\hline Observations & 8531 & 8531 & 16182 & 16179 \\
\hline Other controls & No & Yes & No & Yes \\
\hline \multicolumn{5}{|c|}{ Spell of Incapacity Benefits within 6 months } \\
\hline & \multicolumn{2}{|c|}{ Youths $(16-24)$} & \multicolumn{2}{|c|}{ Adults (25-64) } \\
\hline JSA & -0.006 & -0.007 & 0.009 & 0.007 \\
\hline (s.e) & $(0.012)$ & $(0.011)$ & $(0.011)$ & $(0.010)$ \\
\hline Observations & 8531 & 8531 & 16182 & 16179 \\
\hline Other controls & No & Yes & No & Yes \\
\hline
\end{tabular}

Notes. The sample includes the 1997, 1998, and 1999 cohorts of unemployment entrants. The outcome variable is 1 if a new benefit spell has started within 3 or 6 months since the end of the current spell. Estimation method: probit (marginal effects are reported). $\mathrm{JSA}=\mathrm{C}^{97} * \mathrm{~T}$, and regressions also control for $\mathrm{T}, \mathrm{C}^{97}$ and $\mathrm{C}^{98}$ separately. Other controls included are: age, age squared, total weeks worked in each of the previous 3 years and their square, total earnings in each of the previous 3 years and their square. Standard errors are clustered at the monthly inflow level and reported in brackets. $^{* * * * * *}$ and ${ }^{*}$ denote significance at the $1 \%, 5 \%$ and $10 \%$ levels, respectively. 
Table 5

The impact of JSA on exit into other benefit spells

IV estimates

\begin{tabular}{|c|c|c|c|c|}
\hline \multicolumn{5}{|c|}{ New claimant unemployment spell within 3 months } \\
\hline & \multicolumn{2}{|c|}{ Youths $(16-24)$} & \multicolumn{2}{|c|}{ Adults (25-64) } \\
\hline JSA & $0.047 * *$ & $0.047 * *$ & $0.029 * *$ & $0.029 * *$ \\
\hline (s.e) & $(0.019)$ & $(0.019)$ & $(0.014)$ & $(0.014)$ \\
\hline Observations & 16533 & 16533 & 32771 & 32769 \\
\hline Other controls & No & Yes & No & Yes \\
\hline \multicolumn{5}{|c|}{ Spell of Incapacity Benefits within 3 months } \\
\hline & \multicolumn{2}{|c|}{ Youths $(16-24)$} & \multicolumn{2}{|c|}{ Adults (25-64) } \\
\hline JSA & $0.029 * *$ & $0.029 * *$ & 0.019 & 0.013 \\
\hline (s.e) & $(0.012)$ & $(0.012)$ & $(0.013)$ & $(0.013)$ \\
\hline Observations & 16533 & 16533 & 32771 & 32769 \\
\hline Other controls & No & Yes & No & Yes \\
\hline \multicolumn{5}{|c|}{ New claimant unemployment spell within 6 months } \\
\hline & \multicolumn{2}{|c|}{ Youths $(16-24)$} & \multicolumn{2}{|c|}{ Adults (25-64) } \\
\hline JSA & $0.087 * * *$ & $0.086^{* * *}$ & 0.037 & 0.032 \\
\hline (s.e) & $(0.031)$ & $(0.031)$ & $(0.024)$ & $(0.024)$ \\
\hline Observations & 16533 & 16533 & 32771 & 32769 \\
\hline Other controls & No & Yes & No & Yes \\
\hline \multicolumn{5}{|c|}{ Spell of Incapacity Benefits within 6 months } \\
\hline & \multicolumn{2}{|c|}{ Youths $(16-24)$} & \multicolumn{2}{|c|}{ Adults (25-64) } \\
\hline JSA & $0.044 * * *$ & $0.042 * * *$ & $0.037 * *$ & $0.030 *$ \\
\hline (s.e) & $(0.016)$ & $(0.016)$ & $(0.016)$ & $(0.015)$ \\
\hline Observations & 16533 & 16533 & 32771 & 32769 \\
\hline Other controls & No & Yes & No & Yes \\
\hline
\end{tabular}

Notes. The outcome variable is 1 if a new benefit spell has started within 3 or 6 months since the end of the current spell. Estimation method: IV, where JSA is equal to 1 if a spell ends on or after 7 October 1996, and is instrumented by the distance between Fall 1996 and the quarter of entry. Regressions also control for quarter of entry and yearly cohort of entry. Other controls included are: age, age squared, total weeks worked in each of the previous 3 years and their square, total earnings in each of the previous 3 years and their square. Standard errors are clustered at the monthly inflow level and reported in brackets. ${ }^{* * *},{ }^{* *}$ and ${ }^{*}$ denote significance at the $1 \%, 5 \%$ and $10 \%$ levels, respectively. 
Figure 1:

Flows out of and into the claimant unemployment register

Monthly data seasonally adjusted. Source: NOMIS

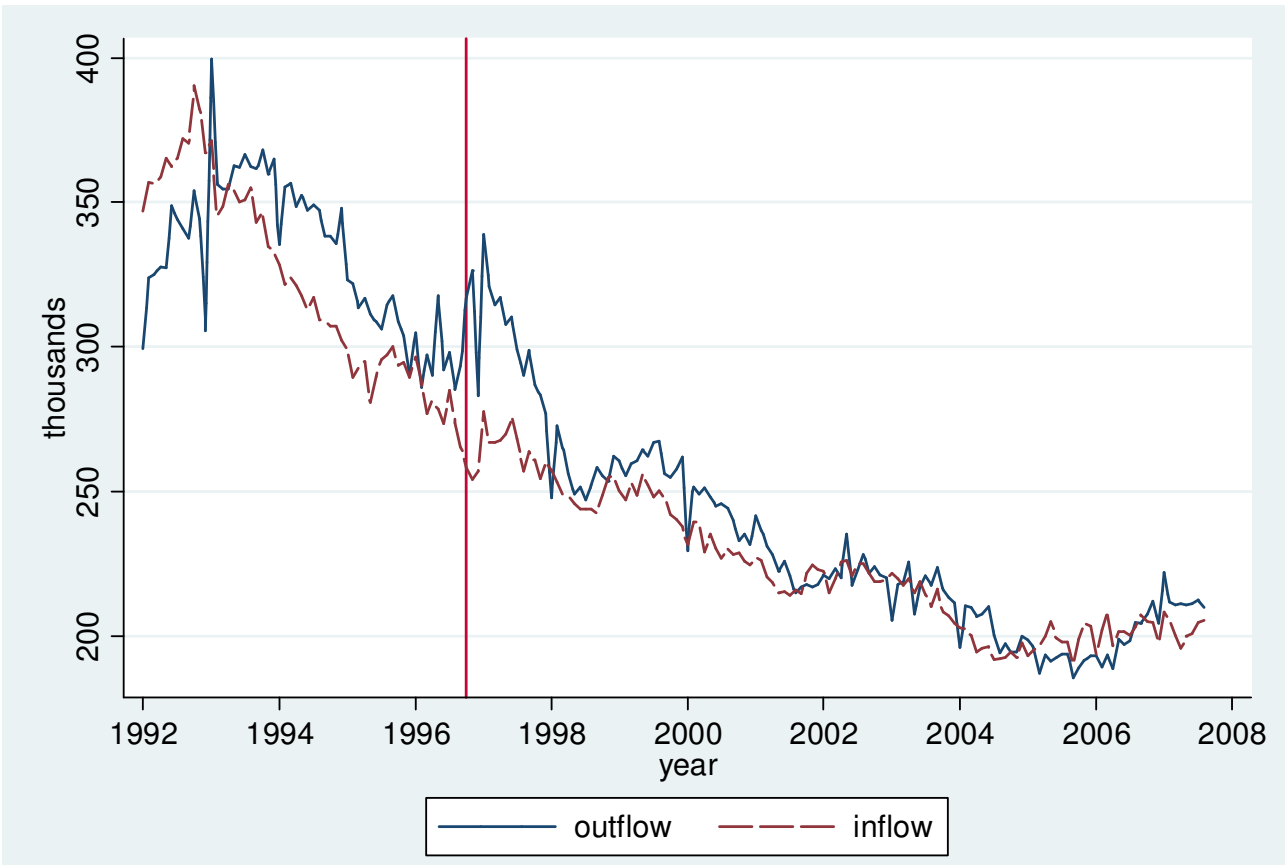

Figure 2:

The claimant count and ILO unemployment

Monthly data seasonally adjusted. Source: NOMIS and Office for National Statistics

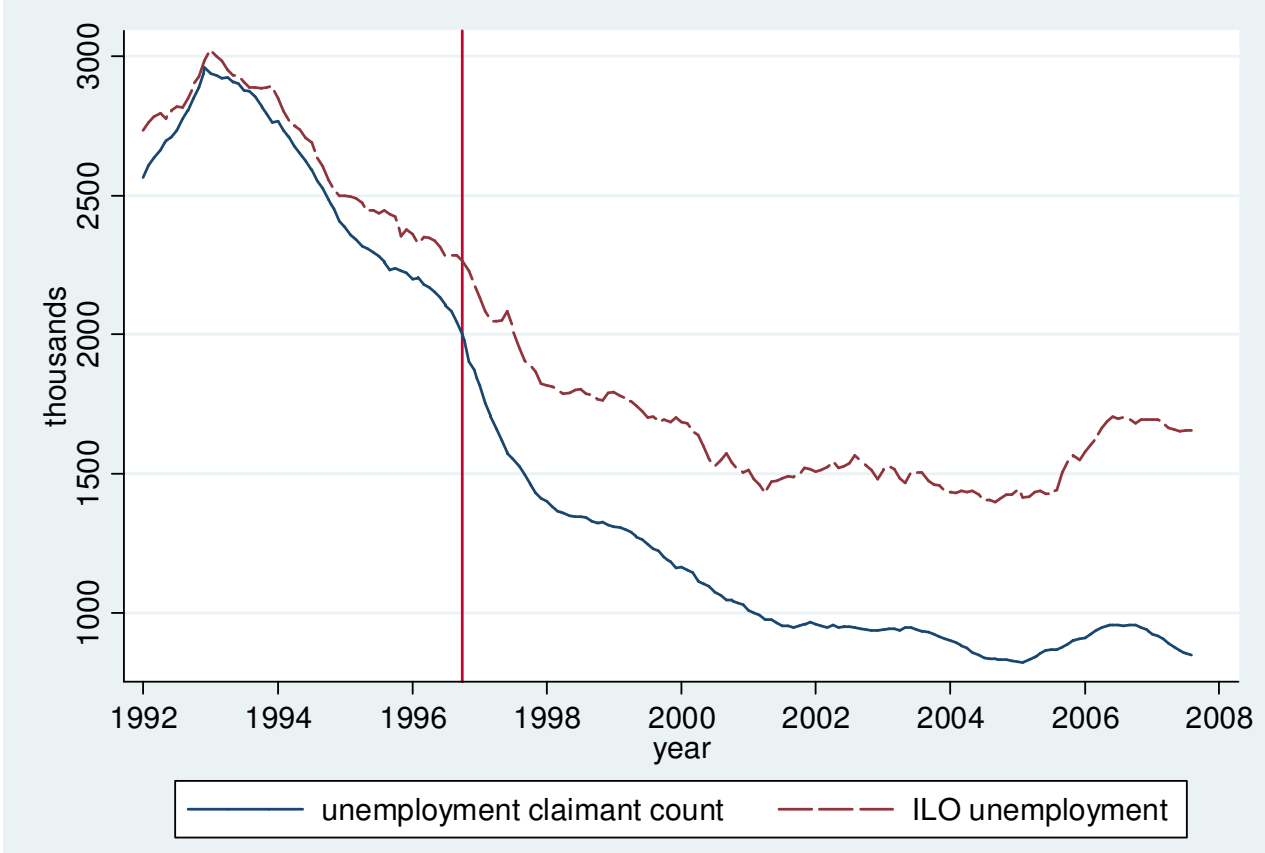


Figure 3:

Registered unemployment and Incapacity Benefits

Quarterly data not seasonally adjusted. Soruce: NOMIS and Department for Work and Pensions.

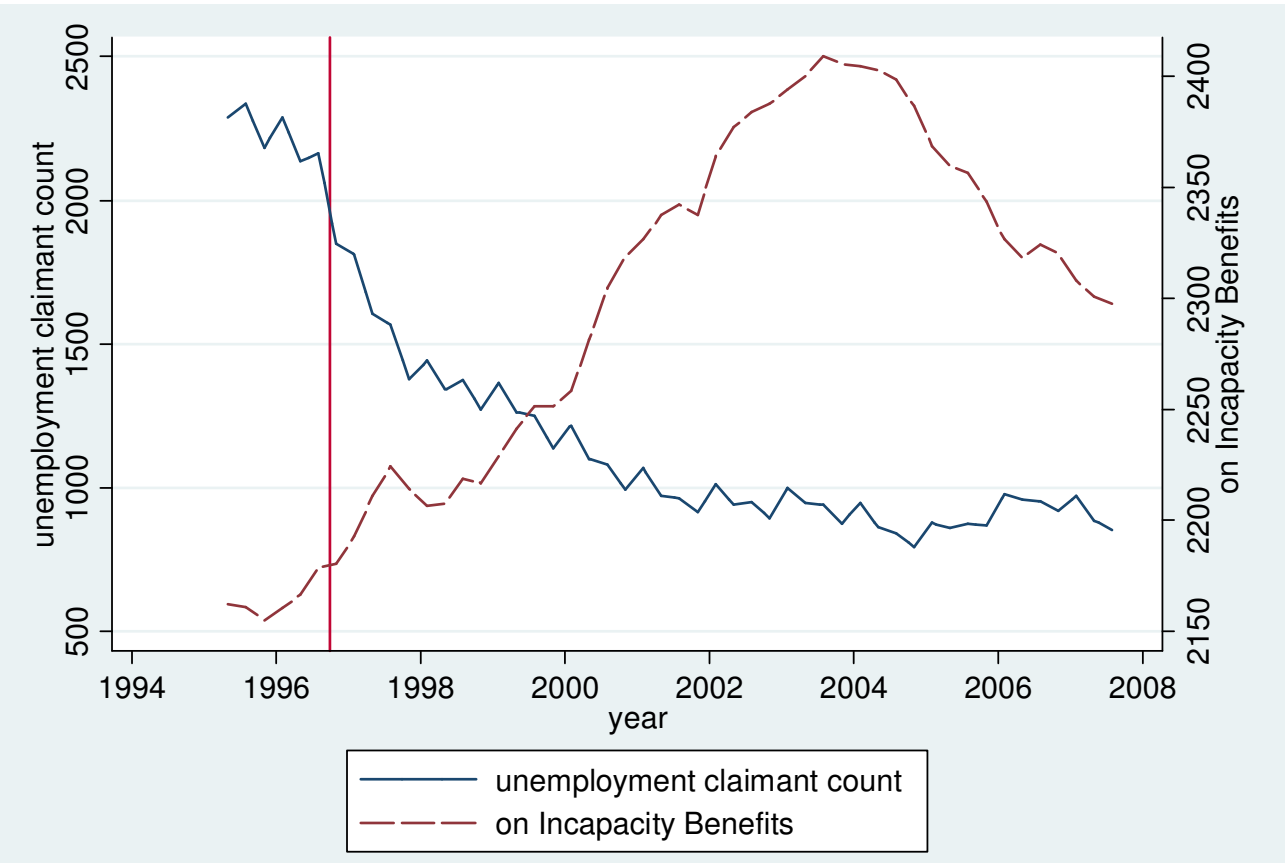

Figure 4

Indifference curves between benefit levels and search effort

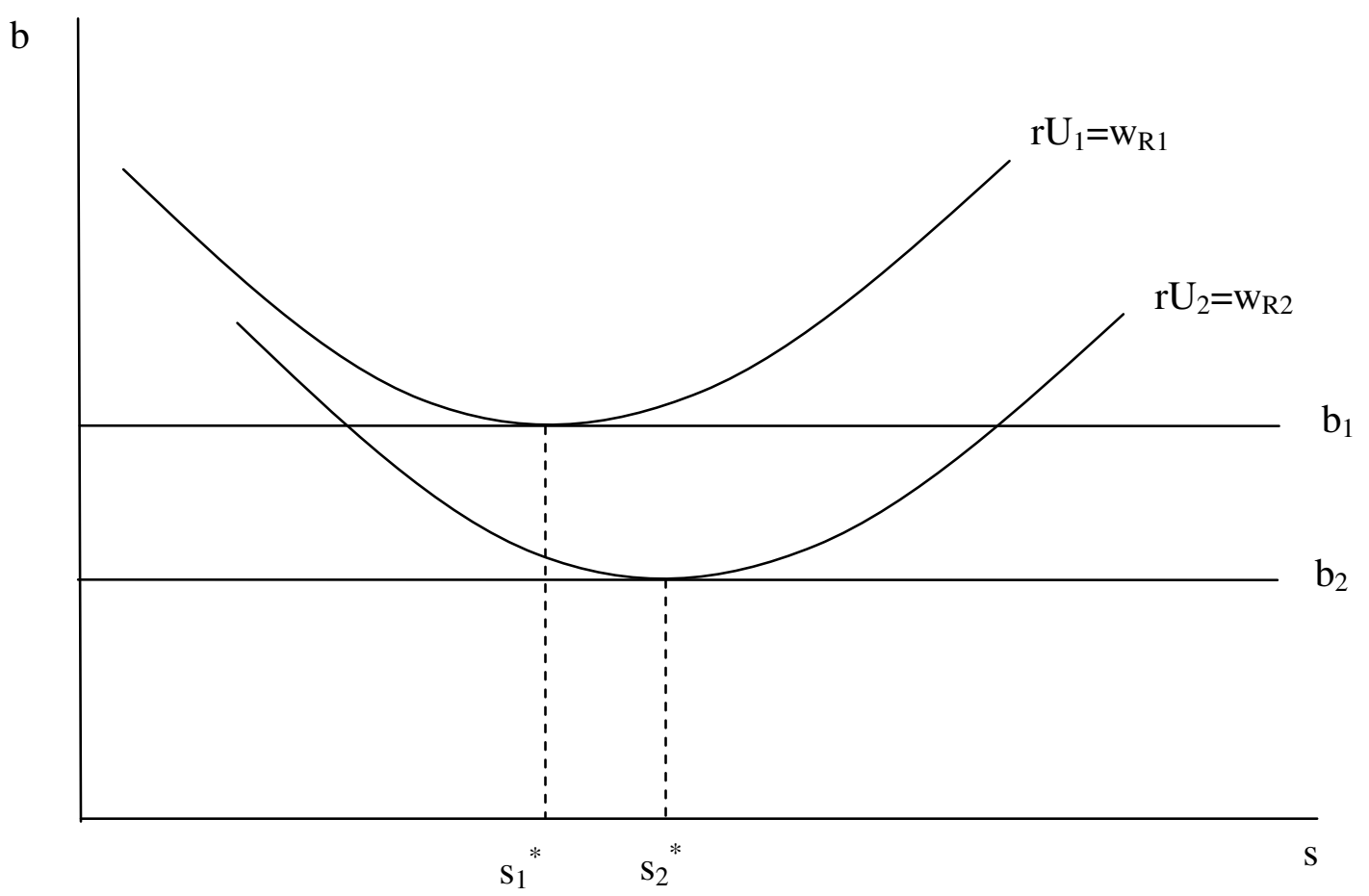


Figure 5

Intended consequences of tighter eligibility requirements

$\mathrm{b}$

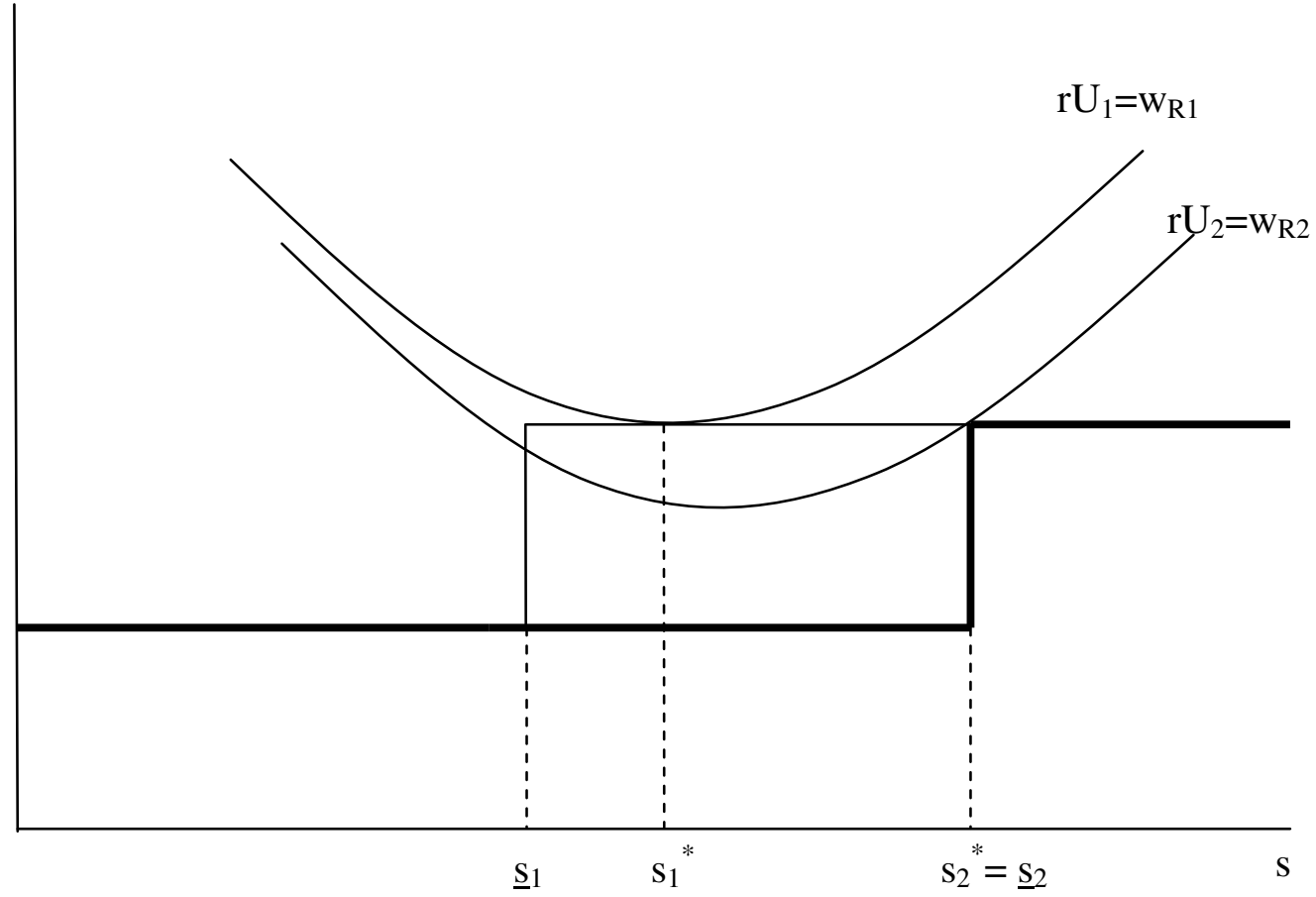

Figure 6

Unintended consequences of tighter eligibility requirements

b

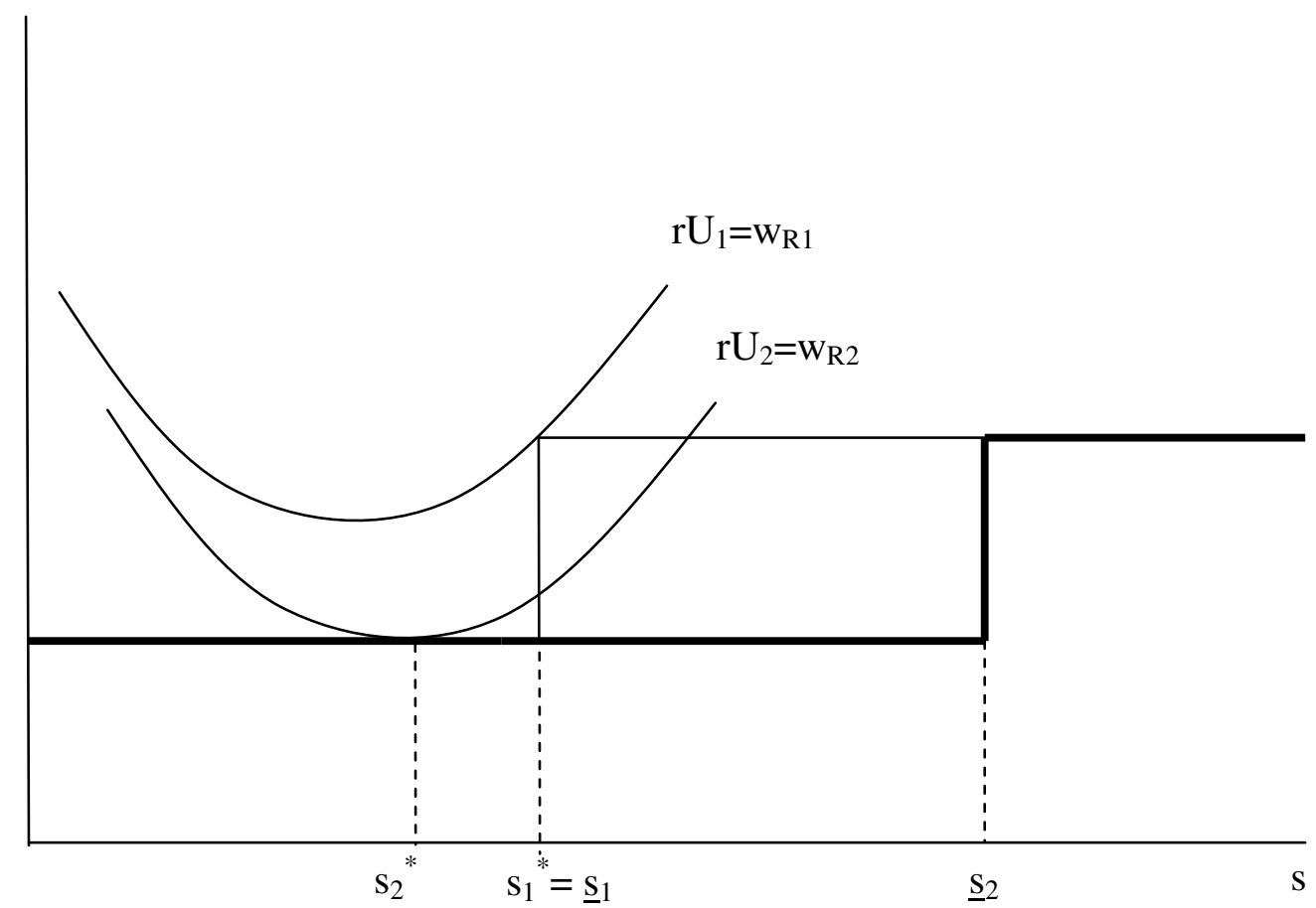


Figure 7

Raw employment and earnings time series from the LLMDB

Sample: males, 16-64.
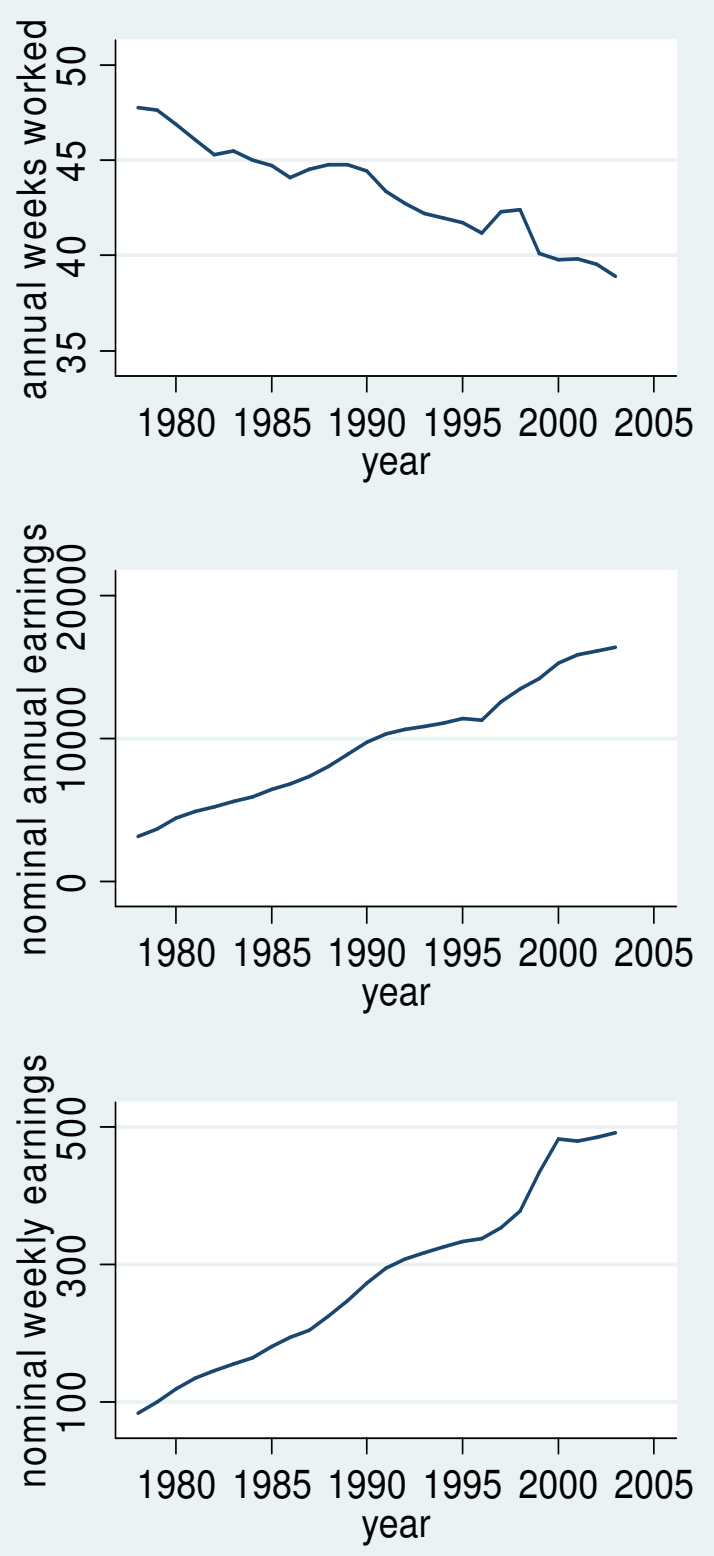


\section{Figure 8}

Claimant unemployment spells started 1 Jan 1996-31 Dec 1998

Daily data aggregated at weekly frequencies. (Source: LLMDB)

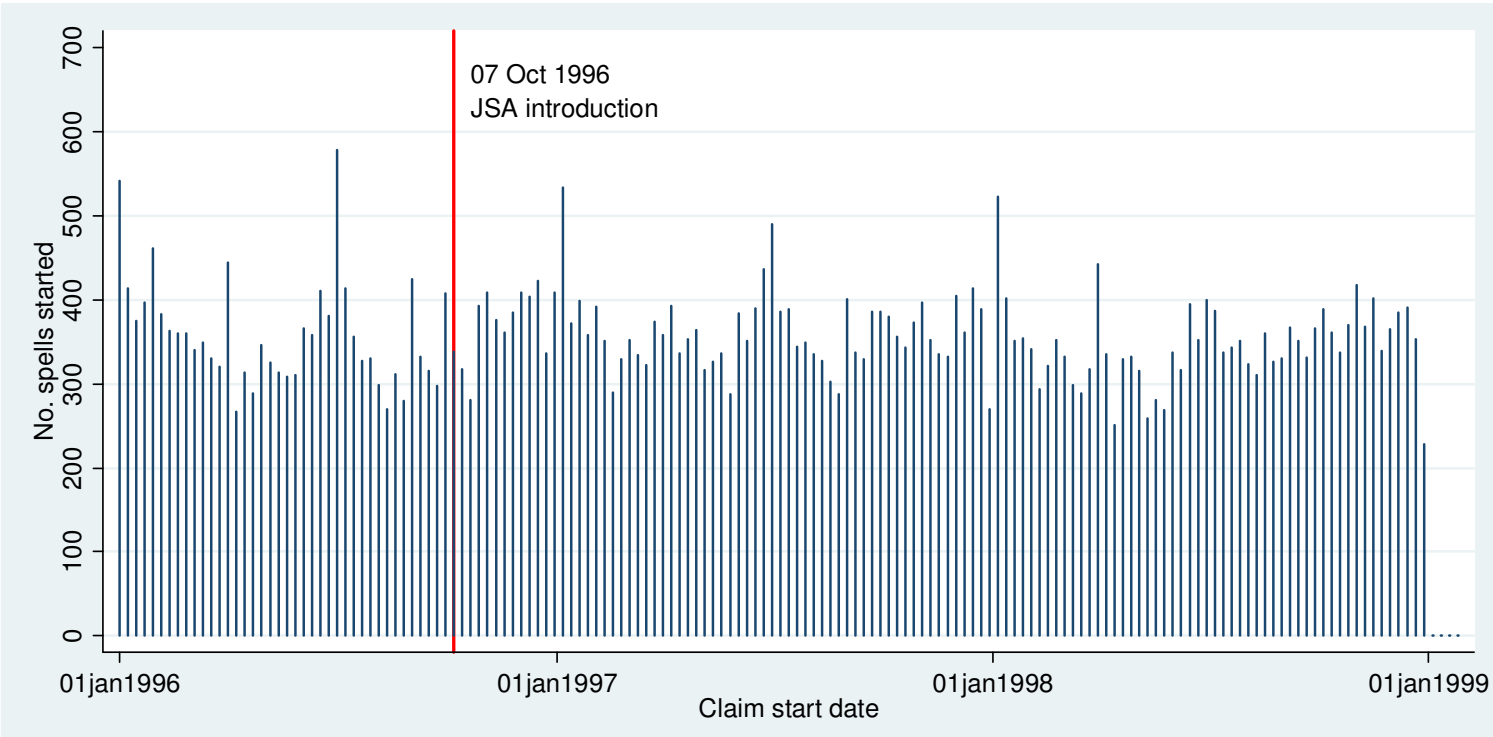

Figure 9

Claimant unemployment spells started 1 Sept -31 Oct 1996.

Daily data. (Source: LLMDB)

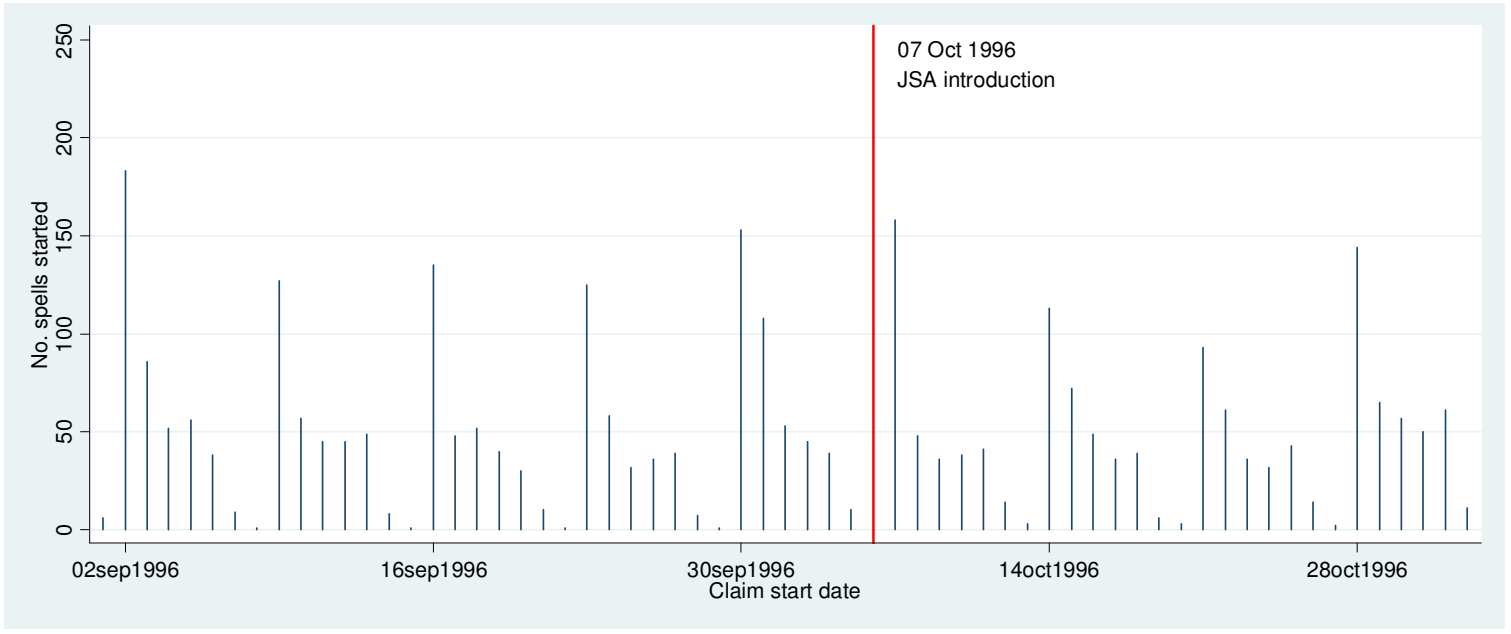

Figure 10

Claimant unemployment spells ended 1 Jan 1996-31 Dec 1998

Daily data aggregated at weekly frequencies. (Source: LLMDB)

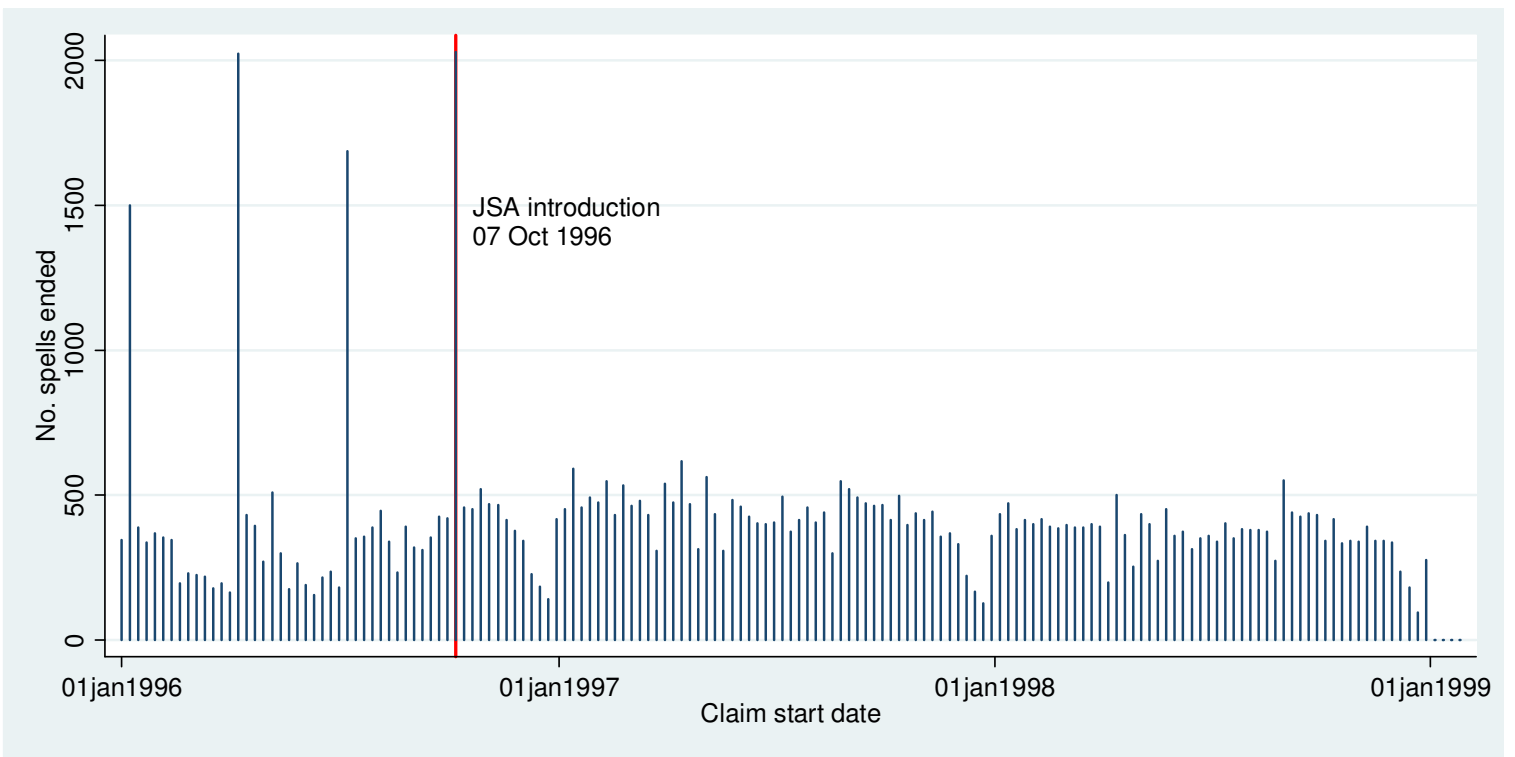


Figure 11

Labor market trends for the Youth sample (16-24)

Source: LLMDB

Panel A: Proportion with positive earnings

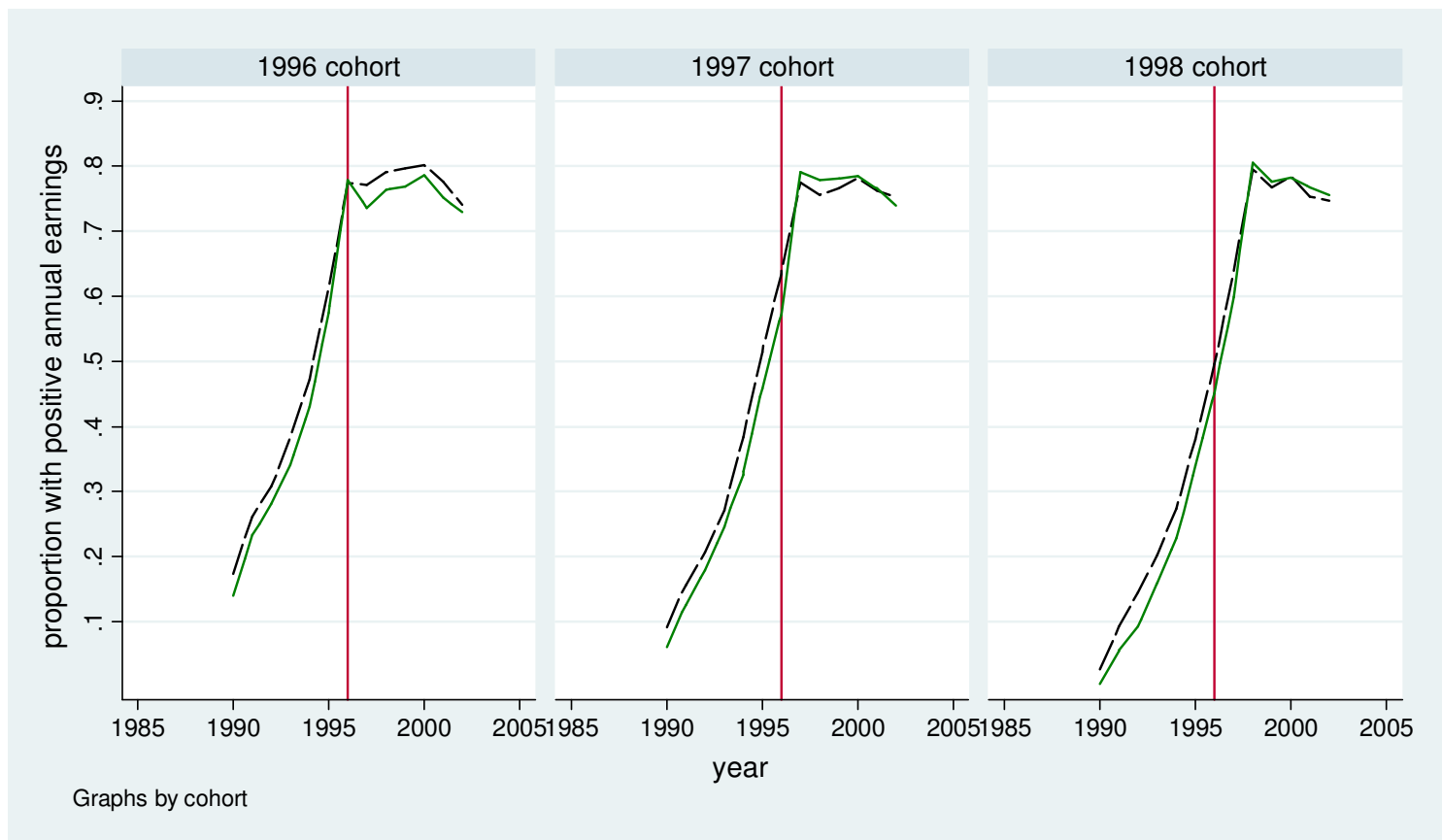

Panel B: Annual earnings

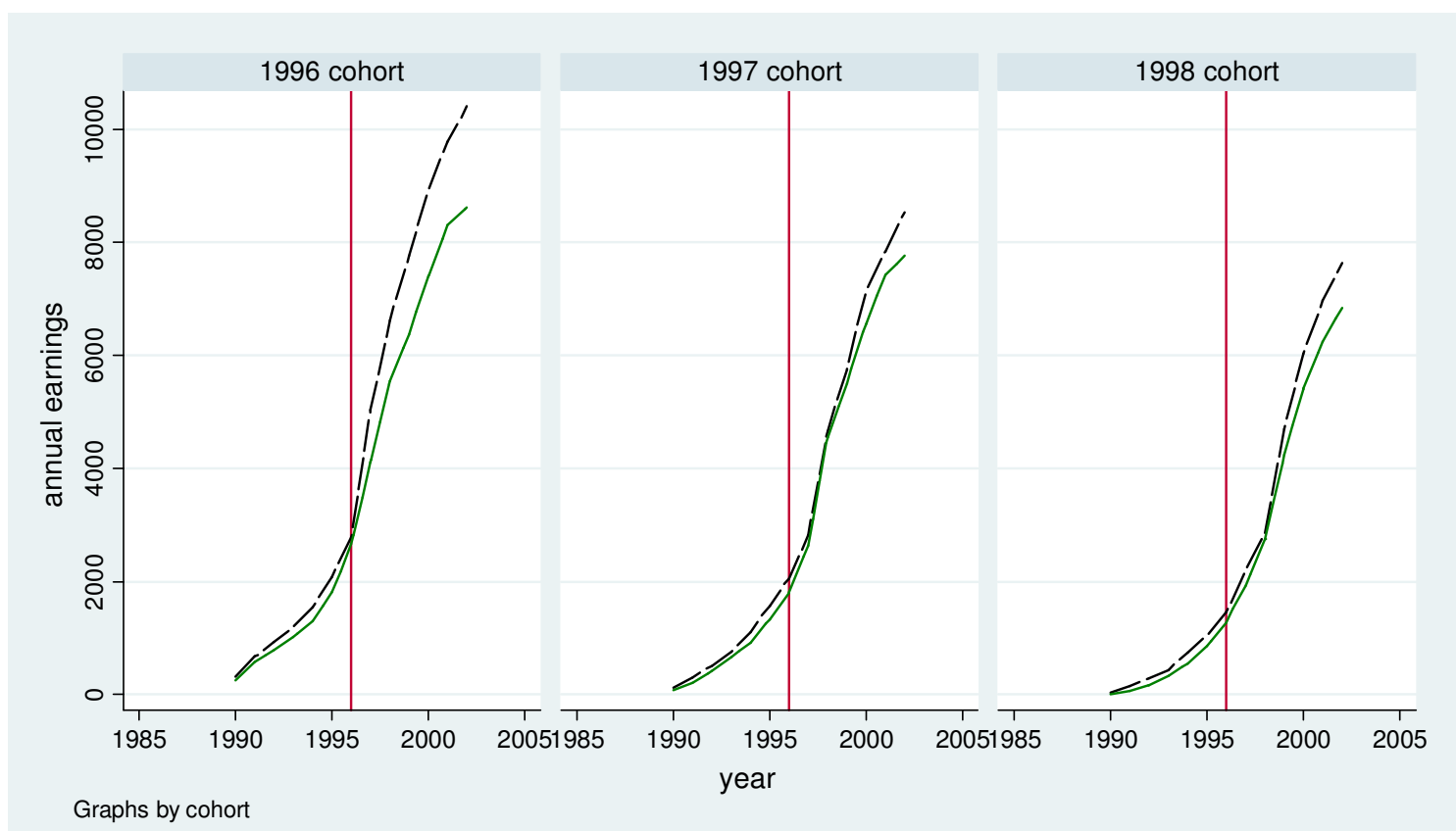


Figure 11 (continued)

Labor market trends for the Youth sample (16-24)

Source: LLMDB

Panel C: Annual weeks worked

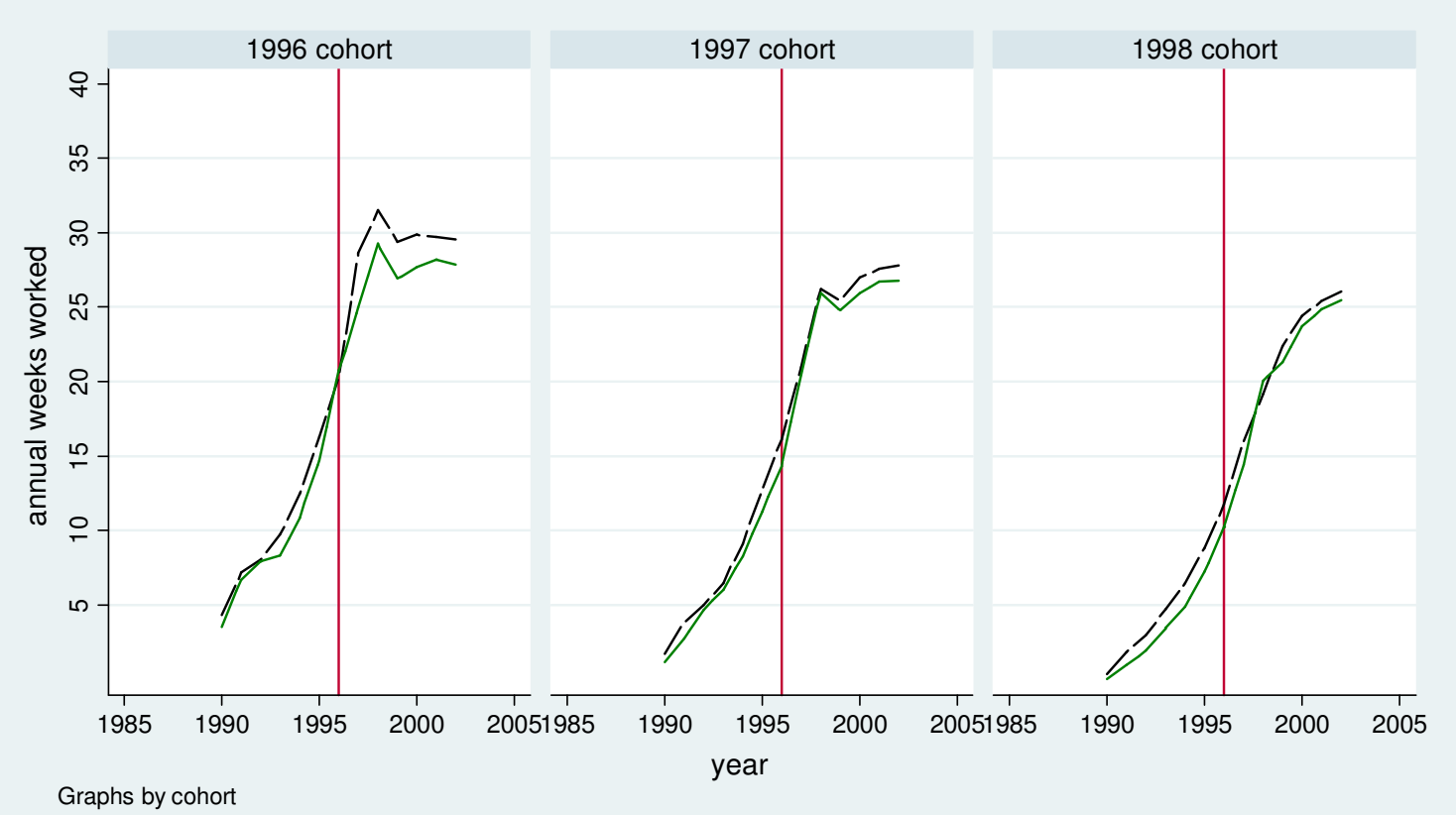

Panel D: Log weekly earnings

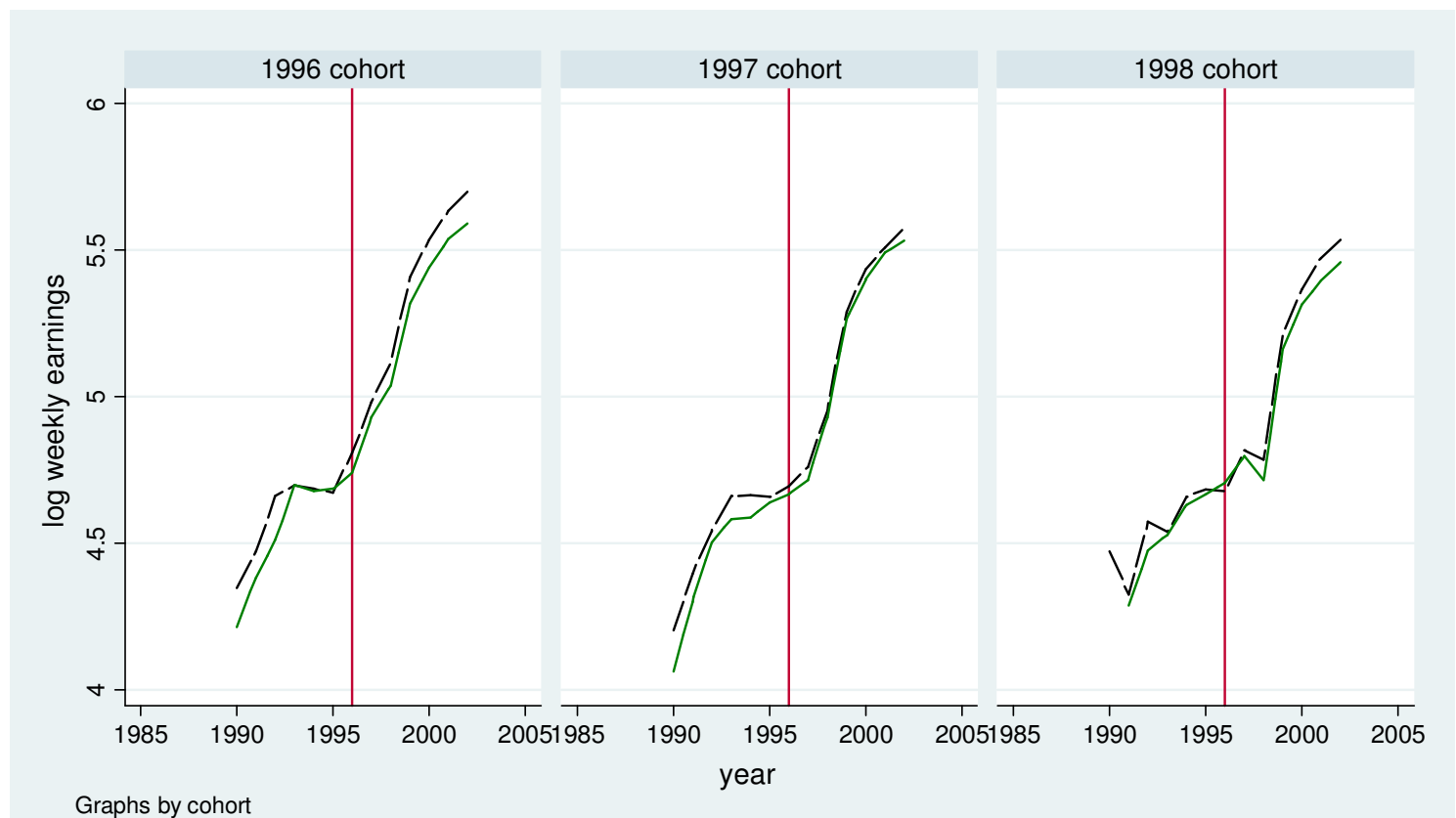

Graphs by cohort 
Figure 12

Labor market trends for the Adult sample (25-64)

Panel A: Proportion with positive earnings

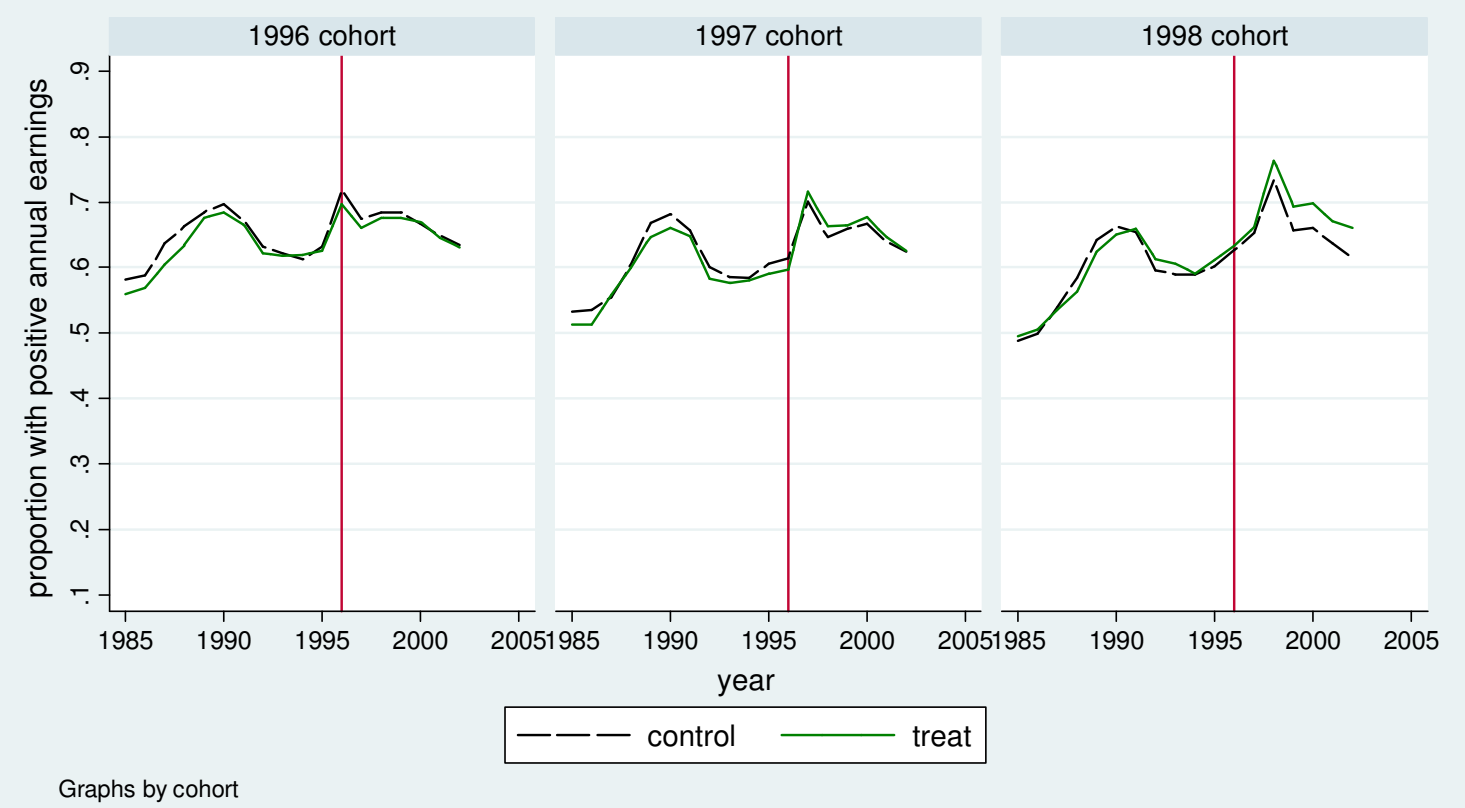

Panel B: Annual earnings

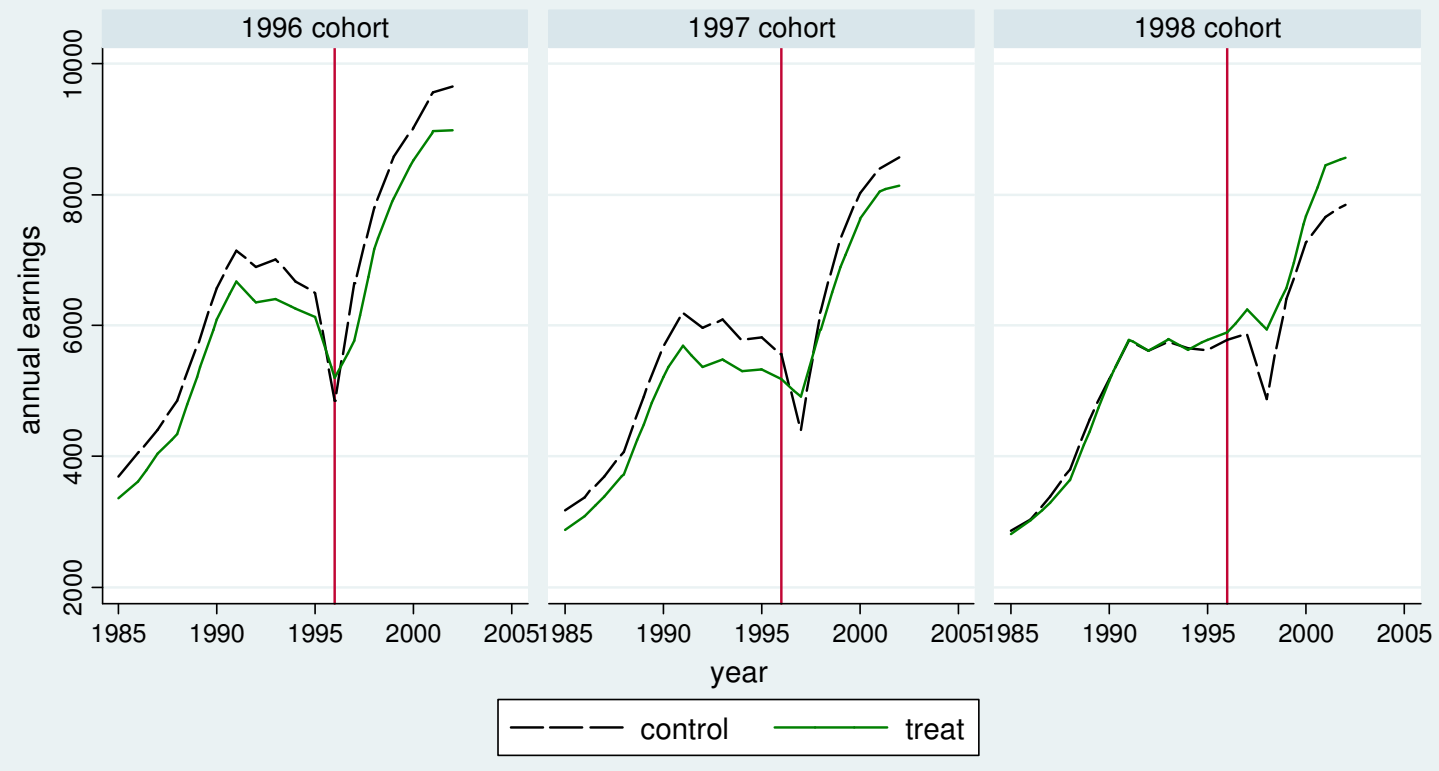

Graphs by cohort 
Figure 12 (continued)

Labor market trends for the Adult sample (25-64)

Panel C: Annual weeks worked

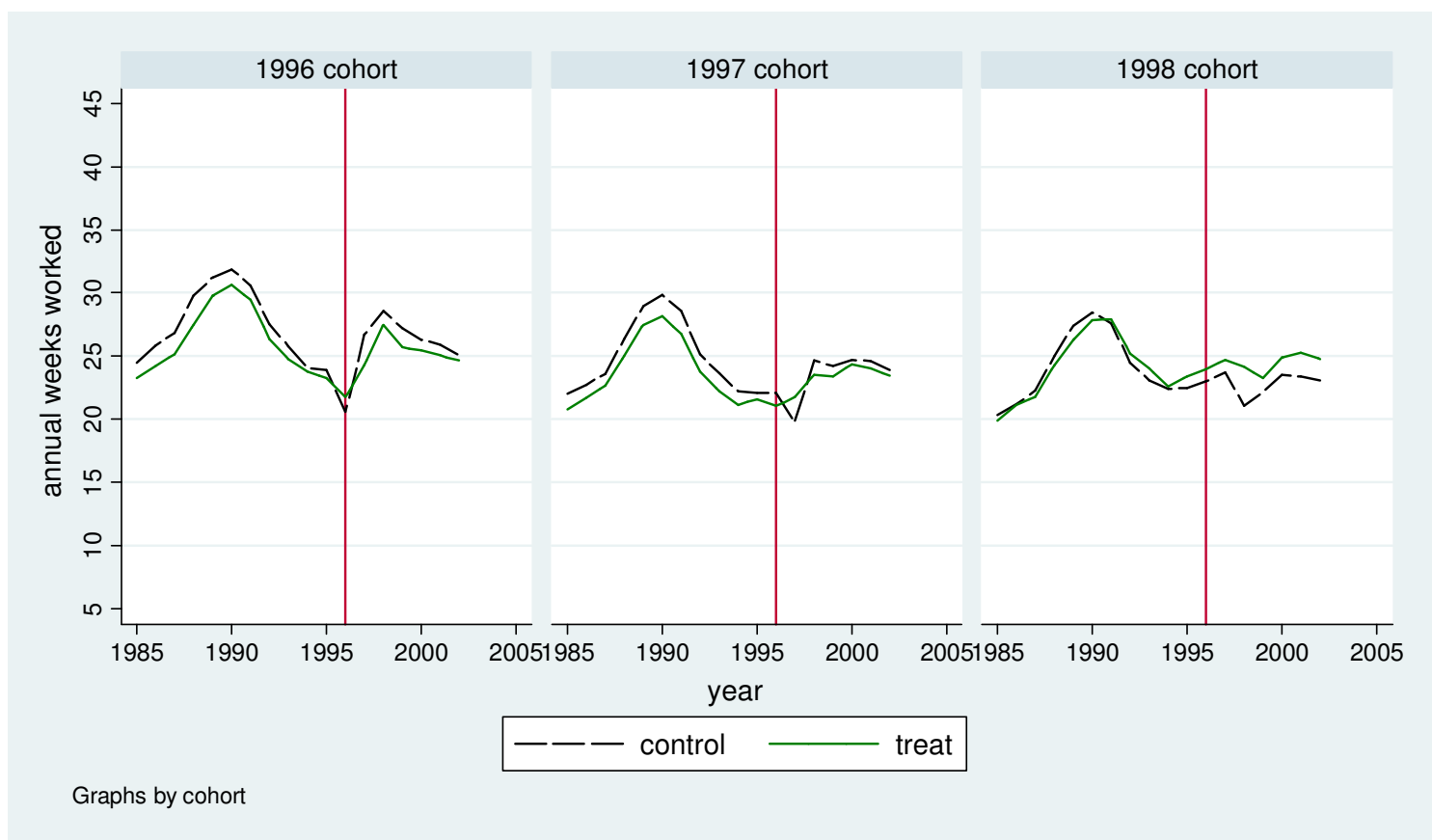

Panel D: Log weekly earnings

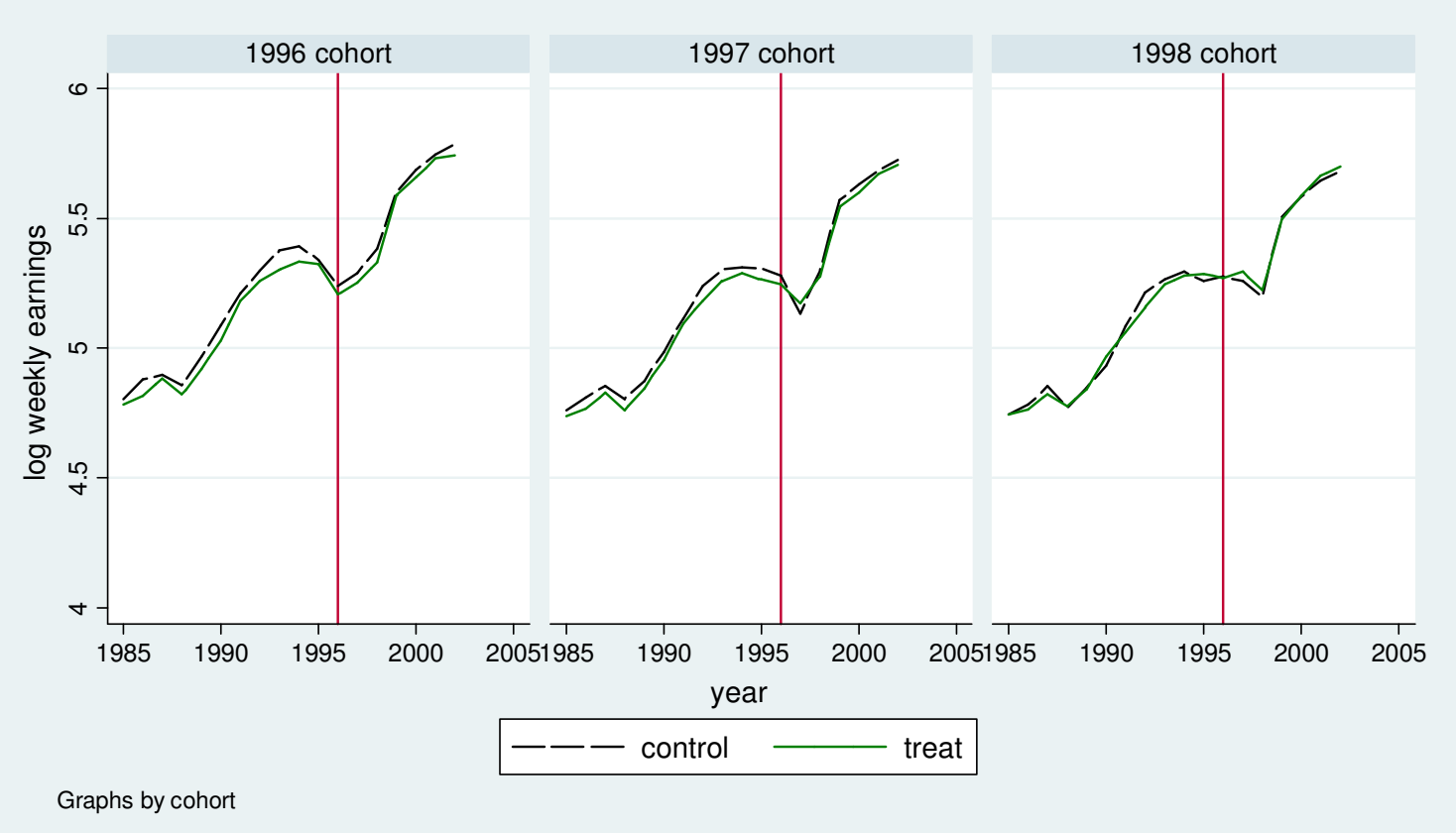


Figure 13

DID in labor market trends. Youth sample (16-24 years old).
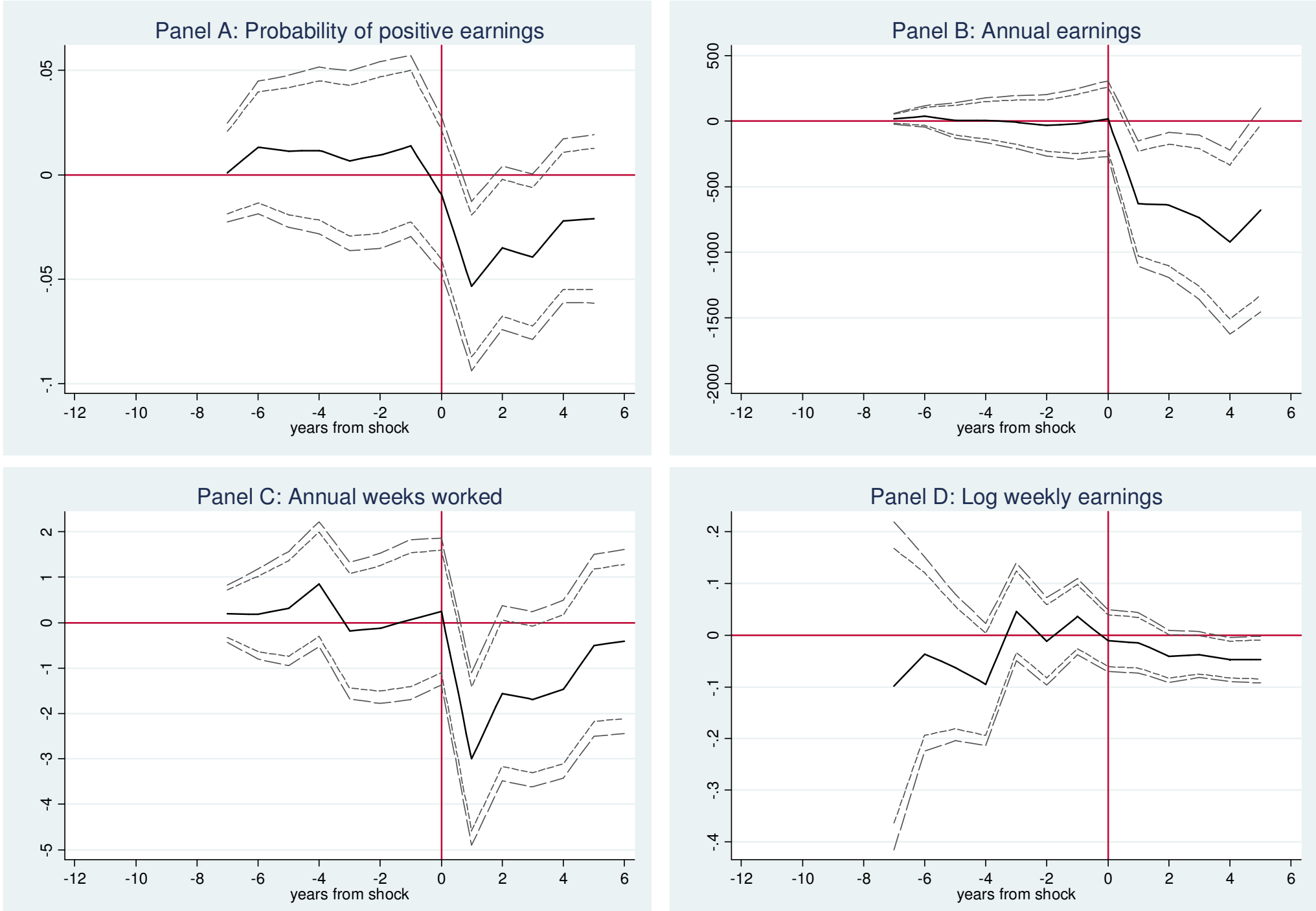

Notes. The solid line represents marginal effects (Panel A) or coefficients (Panels B-D) on the $\mathrm{C}^{96 *} \mathrm{~T}$ interaction (see equation (7)), and regressions also control for T, $\mathrm{C}^{96}$ and $\mathrm{C}^{97}$ separately. The dashed lines represent 90\% and 95\% confidence intervals, with standard errors clustered at the monthly unemployment entry level. Year zero denotes 1996 for the 1996 cohort; 1997 for the 1997 cohort and 1998 for the 1998 cohort. Sample: Males 16-24. Source: LLMDB. 
Figure 14

DID in labor market trends. Adult sample (25-64 years old).
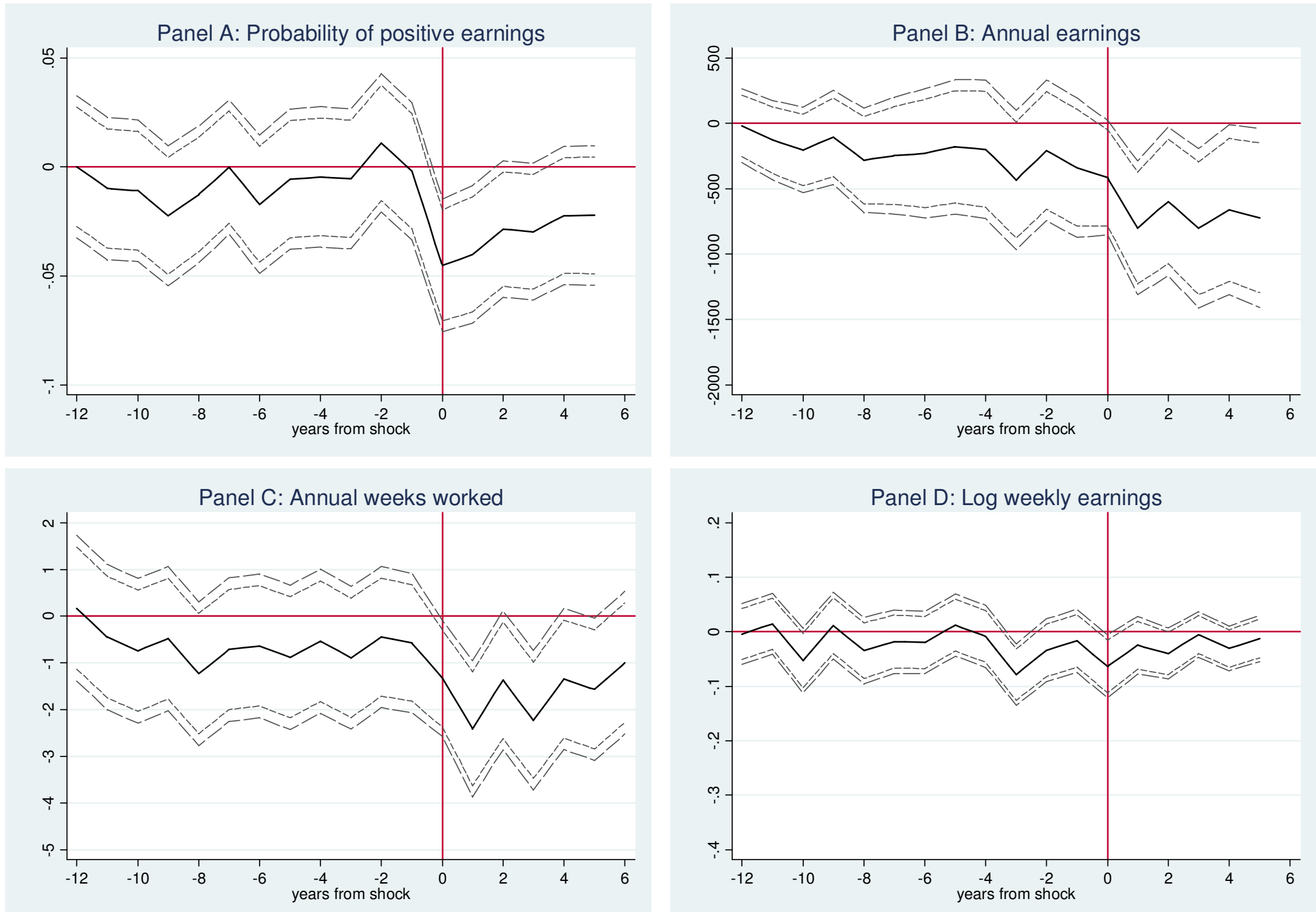

Notes. The solid line represents marginal effects (Panel A) or coefficients (Panels B-D) on the $\mathrm{C}^{96 *} \mathrm{~T}$ interaction (see equation (7)), and regressions also control for T, $\mathrm{C}^{96}$ and $\mathrm{C}^{97}$ separately. The dashed lines represent 90\% and 95\% confidence intervals, with standard errors clustered at the monthly unemployment entry level. Year zero denotes 1996 for the 1996 cohort; 1997 for the 1997 cohort and 1998 for the 1998 cohort. Sample: Males 25-64. Source: LLMDB. 
Figure 15

DID estimates of the effect of JSA on employment and earnings. Youth sample (16-24).
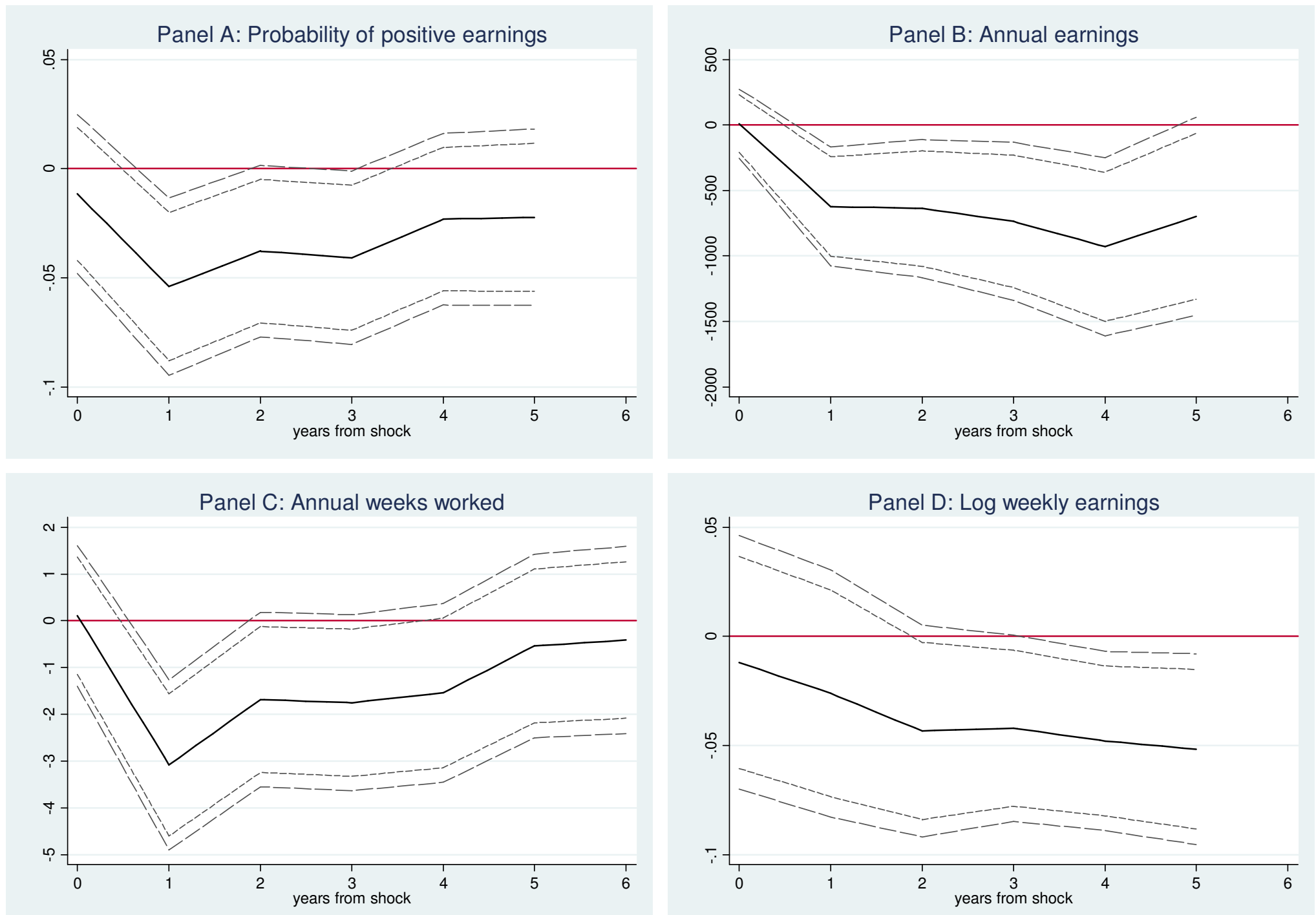

Notes. The solid line represents marginal effects (Panel A) or coefficients (Panels B-D) on the $\mathrm{C}^{96} * \mathrm{~T}$ interaction (see equation (7)), and regressions also control for T, $\mathrm{C}^{96}$ and $\mathrm{C}^{97}$ separately. Other controls included are: age and its square, weeks worked and annual earnings in the three years before the shock and their square. Standard errors are clustered at the monthly inflow level. The dashed lines represent 90\% and 95\% confidence intervals. Year zero denotes 1996 for the 1996 cohort; 1997 for the 1997 cohort and 1998 for the 1998 cohort. Sample: Males 16-24. Source: LLMDB. 
Figure 16

DID estimates of the effect of JSA on employment and earnings. Adult sample (25-64).
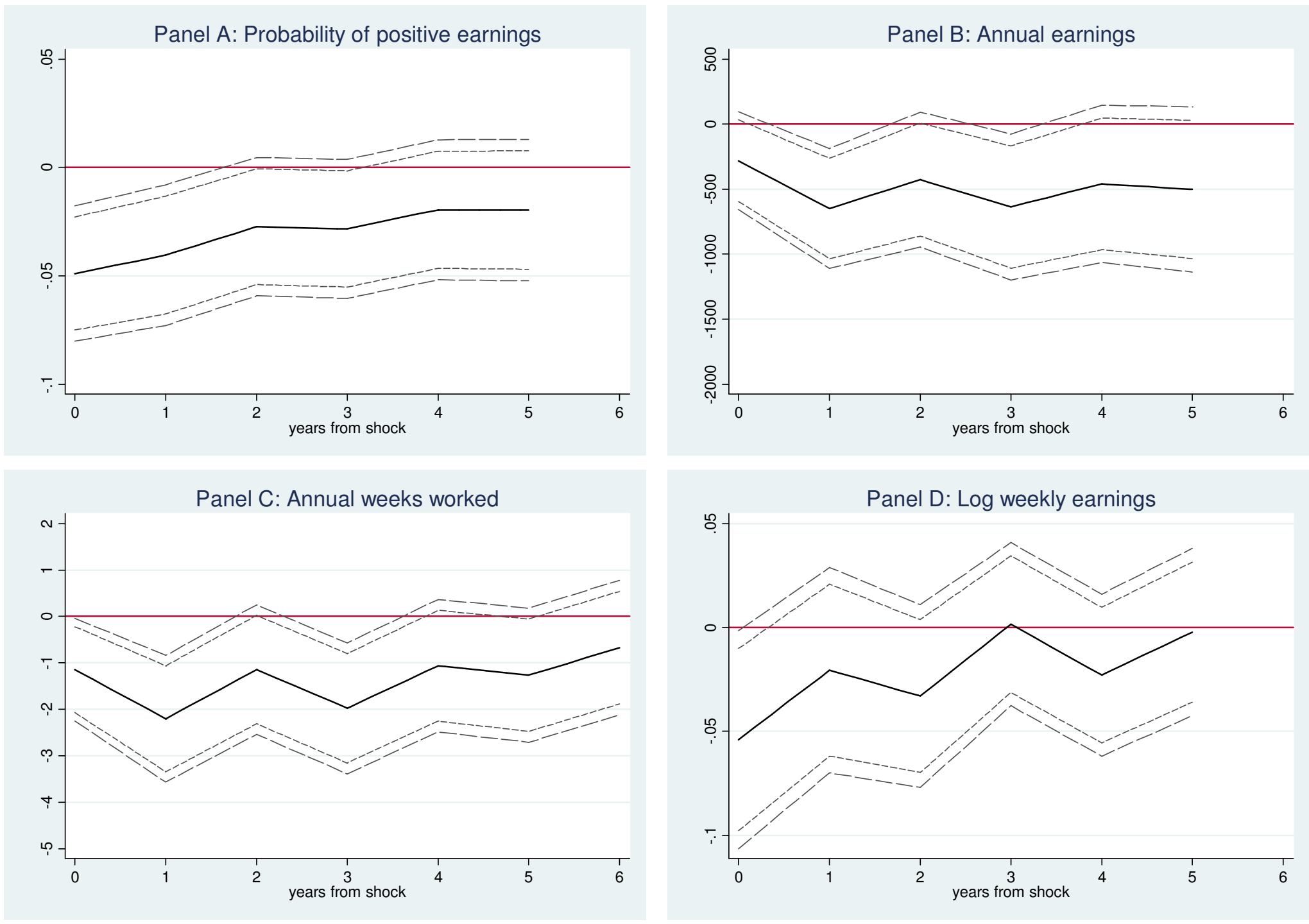

Notes. The solid line represents marginal effects (Panel A) or coefficients (Panels B-D) on the $\mathrm{C}^{96 *} \mathrm{~T}$ interaction (see equation (7)), and regressions also control for T, $\mathrm{C}^{96}$ and $\mathrm{C}^{97}$ separately. Other controls included are: age and its square, weeks worked and annual earnings in the three years before the shock and their square. Standard errors are clustered at the monthly inflow level. The dashed lines represent 90\% and 95\% confidence intervals. Year zero denotes 1996 for the 1996 cohort; 1997 for the 1997 cohort and 1998 for the 1998 cohort. Sample: Males 25-64. Source: LLMDB. 
Figure 17

Falsification test on 1997, 1998 and 1999 cohorts. Youth sample (16-24).
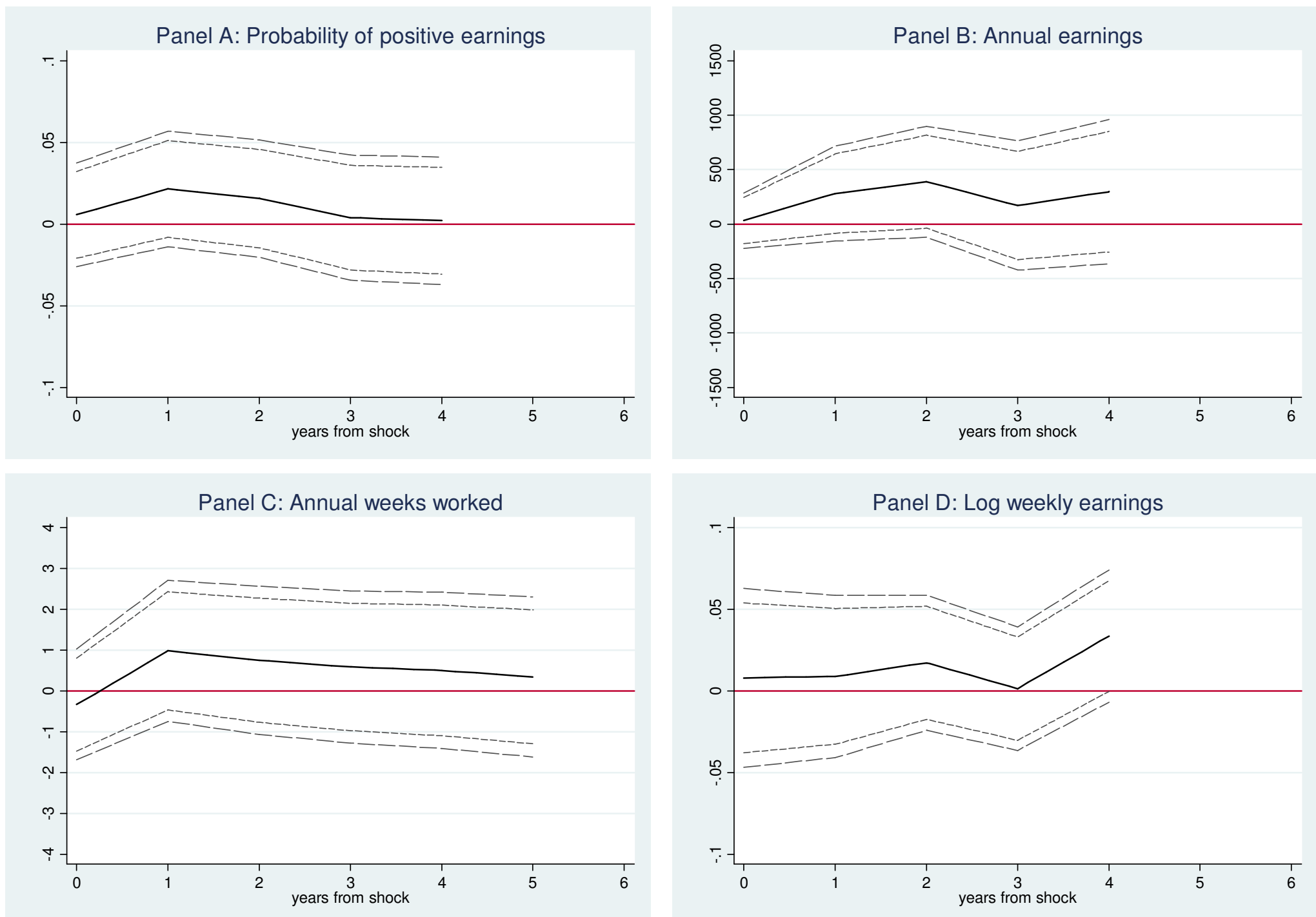

Notes. The sample includes the 1997, 1998 and 1999 unemployment entry cohorts. The solid line represents marginal effects (Panel A) or coefficients (Panels B-D) on the C $\mathrm{C}^{97} * \mathrm{~T}$ interaction, and regressions also control for treatment, $\mathrm{C}^{97}$ and $\mathrm{C}^{98}$ separately. Other controls included are: age and its square, weeks worked and annual earnings in the three years before the shock and their square. Standard errors are clustered at the monthly inflow level. The dashed lines represent 90\% and 95\% confidence intervals. Year zero denotes 1997 for the 1997 cohort; 1998 for the 1998 cohort and 1999 for the 1999 cohort. Sample: Males 16-24. Source: LLMDB. 
Figure 18

Falsification test on 1997, 1998 and 1999 cohorts. Adult sample (25-64).
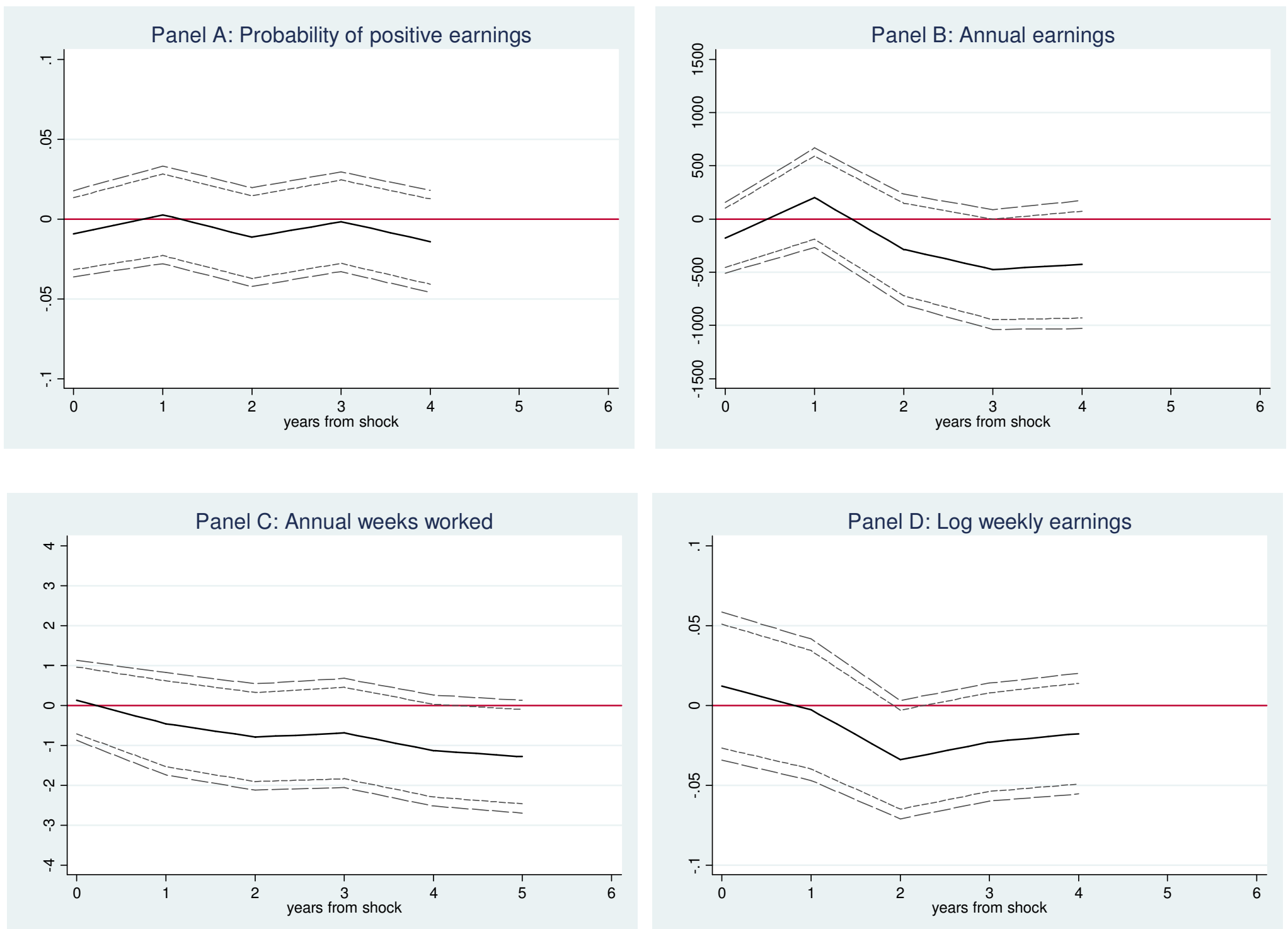

Notes. The sample includes the 1997, 1998 and 1999 unemployment entry cohorts. The solid line represents marginal effects (Panel A) or coefficients (Panels B-D) on the C ${ }^{97} * T$ interaction, and regressions also control for $\mathrm{T}, \mathrm{C}^{97}$ and $\mathrm{C}^{98}$ separately. Other controls included are: age and its square, weeks worked and annual earnings in the three years before the shock and their square. Standard errors are clustered at the monthly inflow level. The dashed lines represent 90\% and 95\% confidence intervals. Year zero denotes 1997 for the 1997 cohort; 1998 for the 1998 cohort and 1999 for the 1999 cohort. Sample: Males 25-64. Source: LLMDB. 
Figure 19

IV estimates of the effect of JSA on employment and earnings. Youth sample (16-24).
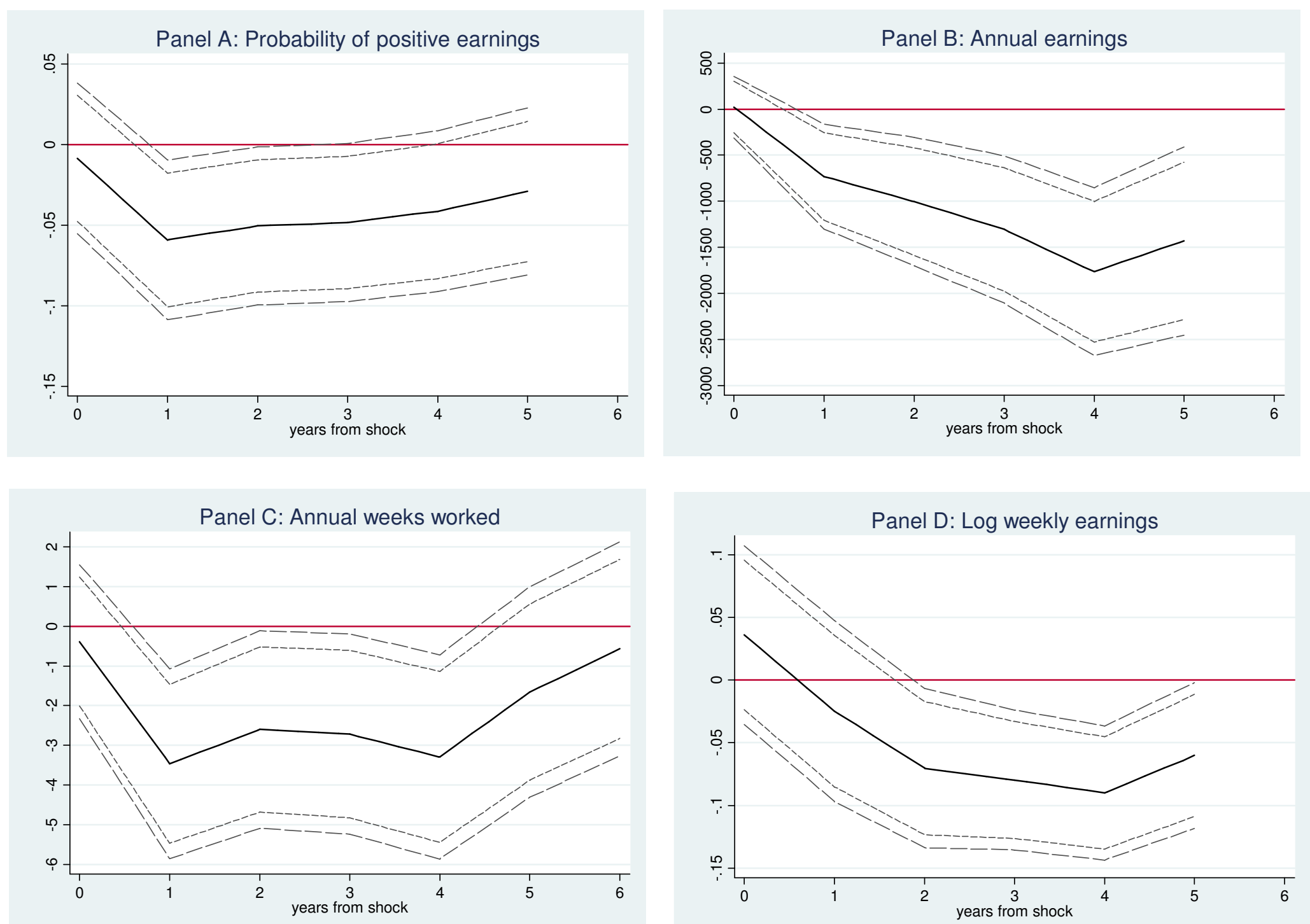

Notes. The solid line represents coefficients on the JSA variable (see equation (8)), where JSA is equal to 1 if a spell ends on or after 7 October 1996, and is instrumented by the distance between Fall 1996 and the quarter of entry. Regressions also control for quarter of entry and yearly cohort of entry. Other controls included are: age and its square, weeks worked and annual earnings in the three years before the shock and their square. Standard errors are clustered at the monthly inflow level. The dashed lines represent $90 \%$ and $95 \%$ confidence intervals. Year zero denotes 1996 for the 1996 cohort; 1997 for the 1997 cohort and 1998 for the 1998 cohort. Sample: Males 16-24. Source: LLMDB. 
Figure 20

IV estimates of the effect of JSA on employment and earnings. Adult sample (25-64).
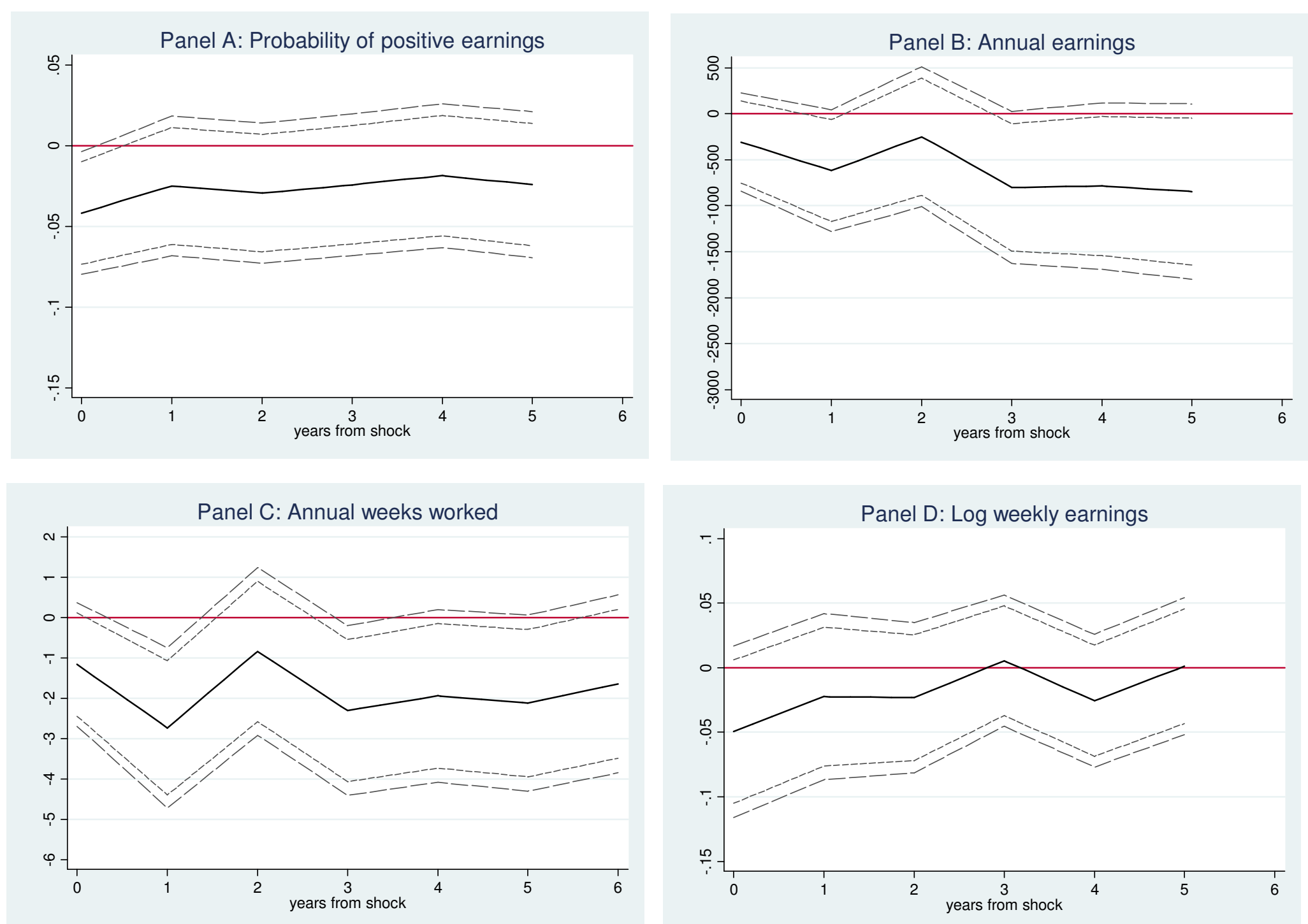

Notes. The solid line represents coefficients on the JSA variable (see equation (8)), where JSA is equal to 1 if a spell ends on or after 7 October 1996 , and is instrumented by the distance between Fall 1996 and the quarter of entry. Regressions also control for quarter of entry and yearly cohort of entry. Other controls included are: age and its square, weeks worked and annual earnings in the three years before the shock and their square. Standard errors are clustered at the monthly inflow level. The dashed lines represent $90 \%$ and $95 \%$ confidence intervals. Year zero denotes 1996 for the 1996 cohort; 1997 for the 1997 cohort and 1998 for the 1998 cohort. Sample: Males 25-64. Source: LLMDB. 